\title{
A Simple Electrochemical Route to Metallic Phase Trilayer MoS2: evaluation as Electrocatalysts and Supercapacitors
}

DOI:

10.1039/C7TA02577G

Document Version

Accepted author manuscript

Link to publication record in Manchester Research Explorer

\section{Citation for published version (APA):}

Aynalem, A., Kinloch, I., Prestat, E., \& Dryfe, R. (2017). A Simple Electrochemical Route to Metallic Phase Trilayer MoS2: evaluation as Electrocatalysts and Supercapacitors. Journal of Materials Chemistry A, 5(22), 11316-11330. https://doi.org/10.1039/C7TA02577G

\section{Published in:}

Journal of Materials Chemistry A

\section{Citing this paper}

Please note that where the full-text provided on Manchester Research Explorer is the Author Accepted Manuscript or Proof version this may differ from the final Published version. If citing, it is advised that you check and use the publisher's definitive version.

\section{General rights}

Copyright and moral rights for the publications made accessible in the Research Explorer are retained by the authors and/or other copyright owners and it is a condition of accessing publications that users recognise and abide by the legal requirements associated with these rights.

\section{Takedown policy}

If you believe that this document breaches copyright please refer to the University of Manchester's Takedown Procedures [http://man.ac.uk/04Y6Bo] or contact uml.scholarlycommunications@manchester.ac.uk providing relevant details, so we can investigate your claim.

\section{OPEN ACCESS}




\section{Journal of \\ Materials Chemistry A}

\section{Accepted Manuscript}

This article can be cited before page numbers have been issued, to do this please use: A. Ejigu, I. A. Kinloch, E. Prestat and R. Dryfe, J. Mater. Chem. A, 2017, DOI: 10.1039/C7TA02577G.

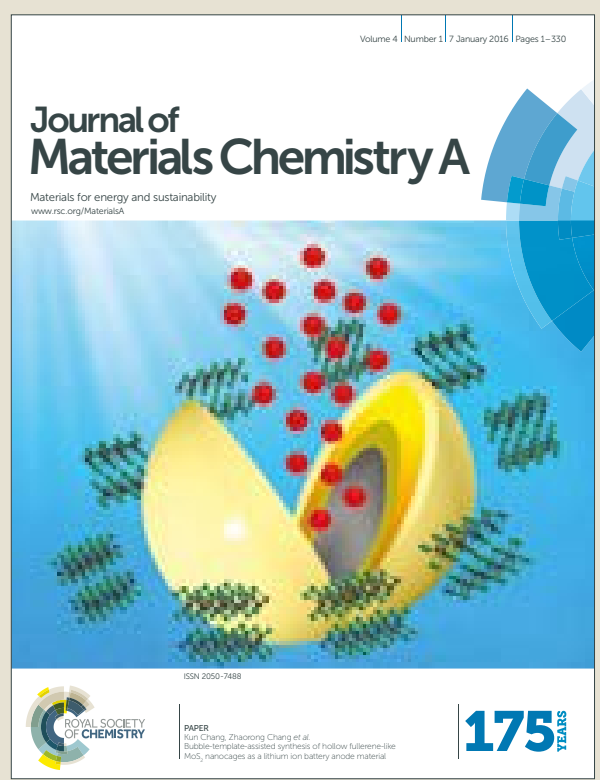

This is an Accepted Manuscript, which has been through the Royal Society of Chemistry peer review process and has been accepted for publication.

Accepted Manuscripts are published online shortly after acceptance, before technical editing, formatting and proof reading. Using this free service, authors can make their results available to the community, in citable form, before we publish the edited article. We will replace this Accepted Manuscript with the edited and formatted Advance Article as soon as it is available.

You can find more information about Accepted Manuscripts in the author guidelines.

Please note that technical editing may introduce minor changes to the text and/or graphics, which may alter content. The journal's standard Terms \& Conditions and the ethical guidelines, outlined in our author and reviewer resource centre, still apply. In no event shall the Royal Society of Chemistry be held responsible for any errors or omissions in this Accepted Manuscript or any consequences arising from the use of any information it contains. 


\section{Journal Name}

\section{ARTICLE}

\section{A Simple Electrochemical Route to Metallic Phase Trilayer $\mathrm{MoS}_{2}$ : evaluation as Electrocatalysts and Supercapacitors}

\author{
Received 00th January \\ 20xx, \\ Accepted 00th January \\ 20xx \\ DOI: $10.1039 / x 0 x x 00000 x$ \\ www.rsc.org/
}

\begin{abstract}
Andinet Ejigu ${ }^{* a, c}, \operatorname{lan}$ A. Kinloch ${ }^{b, c}$, Eric Prestat ${ }^{b}$ and Robert A.W. Dryfe ${ }^{*^{a, c}}$
ABSTRACT-The development of simple, scalable and reproducible technique for the synthesis of two dimensional MoS nanosheets is of paramount importance in the field of catalysis and energy storage devices. Current routes to produce $\mathrm{MoS}_{2}$ nanosheets in reasonable quantities involve either use solution exfoliation of bulk $\mathrm{MoS}_{2}$ or the intercalation of organo-lithium into bulk $\mathrm{MoS}_{2}$ which then subsequently exfoliated by immersing it in water. The former process produces semiconducting $2 \mathrm{H}-\mathrm{MoS}_{2}$ nanoplatelets with smaller lateral flake size whereas the latter process produces highly conducting metallic (1T) phase monolayer $\mathrm{MoS}_{2}$. 1T-MoS nanosheets have high catalytic activity for hydrogen evolution reaction (HER) and are efficient electrode materials for supercapacitor when compared to the $2 \mathrm{H}$ phase. However, the feasibility of producing $1 \mathrm{~T}-\mathrm{MoS}_{2}$ by organolithium intercalation is undermined by the long reaction time (2-3 days) and by its pyrophoric nature. We report a simple, bench-top electrochemical process to produce exfoliated metallic phase MoS within two hours. By using an inert $\mathrm{Li}$ salt $\left(\mathrm{LiClO}_{4}\right)$ as a source of lithium and a Pt counter electrode, an electrochemically lithium intercalated $\mathrm{MoS}_{2}$ electrode was obtained which was subsequently exfoliated by immersing in water Characterization of the exfoliated product using a variety of methods confirmed the formation of the 1T-phase. Remarkably, flake thickness measurement using atomic force microscopy and high-resolution transmission electron microscopy revealed that the majority of the nanosheets are trilayers. The $1 \mathrm{~T}-\mathrm{MoS}_{2}$ nanosheets showed enhanced electrocatalytic activity towards hydrogen evolution compared to $2 \mathrm{H}-\mathrm{MoS}_{2}$ and are efficient materials for supercapacitor applications. Coin cells constructed from a 1T-MoS 2 -graphene composite achieved a volumetric capacitance of over $560 \mathrm{~F}$ $\mathrm{cm}^{-3}$ in an aqueous system and $250 \mathrm{~F} \mathrm{~cm}^{-3}$ in a non-aqueous electrolyte with capacity retention of over $90 \%$ after 5,000 cycles. This process is readily scalable and should ultimately support production of metallic $\mathrm{MoS}_{2}$ for various applications. It can also be extended for producing $2 \mathrm{H}-\mathrm{MoS}_{2}$ nanosheets by heating the exfoliated $1 \mathrm{~T}$ phase.
\end{abstract}

1.Introduction. The evolution of a more sustainable, environmentally benign energy supply is a key for future development and economic growth. There is an urgent need for energy storage and conversion devices (ESCs) that would be available in quantities, and at a cost, that is competitive with fossil fuels. Typical ESCs include solar cells, fuel cells, water electrolysers, supercapactors and rechargeable batteries. Widespread adoption of these technologies is currently hindered by several factors including performance, material stability and cost. ${ }^{1}$ At the heart of these issues are the properties of the nanostructured materials employed in such devices. ${ }^{2}$ The successful development of new nanostructured materials in this regard would represent a key step forward in ESCs technology. Recently, two-dimensional materials such as graphene and $\mathrm{MoS}_{2}$ have shown great promise in ESCs applications because of their high surface area and properties that are distinct from their bulk counterparts. ${ }^{34}$

\footnotetext{
a. School of Chemistry, the University of Manchester, Oxford Road, M13 9PL, UK, b. email-andinet.aynalem@manchester.ac.uk and robert.dryfe@manchester.ac.uk ${ }^{b}$ School of Materials, the University of Manchester, Oxford Road, M13 9PL, UK. ${ }^{c}$ National Graphene Institute, the University of Manchester, Oxford Road, M13 gPL, UK.

+ Electronic Supplementary Information (ESI) available: [high resolution TEM image, SEM image and XRD of $1 T-\mathrm{MOS}_{2}$ and $1 \mathrm{~T}-\mathrm{MoS}_{2} /$ graphene, cyclic voltammograms of $1 \mathrm{~T}-\mathrm{MoS}_{2} /$ graphene in $6.0 \mathrm{M} \mathrm{KOH} \mathrm{(aq)} \mathrm{and} 1.0 \mathrm{M}[\mathrm{TEA}]\left[\mathrm{BF}_{4}\right]$ in $\mathrm{PC}$, Table on energy and power density of $1 \mathrm{~T}-\mathrm{MoS}_{2} /$ graphene and video showing $\mathrm{MoS}_{2}$ exfoliation]. See DOI: 10.1039/x0xx00000x
}

Layered molybdenum disulfide exhibits two possible phases, the naturally occurring semiconducting phase $\left(2 \mathrm{H}-\mathrm{MoS}_{2}\right)$, and a non-naturally occurring metallic state $\left(1 \mathrm{~T}-\mathrm{MoS}_{2}\right)$ that can be prepared by intercalation chemistry. ${ }^{5}$ The $2 \mathrm{H}$ phase is semiconducting with a direct bandgap of $\sim 1.9 \mathrm{eV}$ for monolayer sheets. ${ }^{6}$ The $1 \mathrm{~T}$ phase though is metallic with a conductivity up to $10^{7}$ times higher than the $2 \mathrm{H}$ phase. ${ }^{7}$ Metallic phase $\mathrm{MoS}_{2}$ nanosheets are very attractive for a number of electrochemical applications including as supercapacitor electrodes, as catalysts for hydrogen evolution and in dye-sensitised solar cells. ${ }^{7-11}$ For example, Chhowalla et al. recently demonstrated that the gravimetric capacitance of chemically exfoliated $1 \mathrm{~T}-\mathrm{MoS}_{2}$ in aqueous electrolyte was 20 times higher than that of the $2 \mathrm{H}$ phase. ${ }^{7}$ The ability of $1 \mathrm{~T}-\mathrm{MoS}_{2}$ to intercalate various ions, coupled with its high electrical conductivity and hydrophilicity, were suggested as reasons for this good performance. ${ }^{7}$ In the case of the hydrogen evolution reaction (HER), unlike the $2 \mathrm{H}-\mathrm{MoS}_{2}$ where the basal plane is catalytically inert towards HER, the basal plane of $1 \mathrm{~T}-\mathrm{MoS}_{2}$ was found to be the main active site for HER resulting in a significant enhancement in the overall catalytic activity. ${ }^{9,12}$ The development of a simple and efficient route for synthesizing this material therefore is key to harnessing its potential. To this end, a few synthetic methods have been reported to produce $1 \mathrm{~T}-\mathrm{MoS}_{2}$ including top-down (chemical exfoliation) and bottom-up (hydrothermal synthesis) approaches. ${ }^{11,13,14}$

The most common method for producing $1 \mathrm{~T}-\mathrm{MoS}_{2}$ nanosheets involves organolithium intercalation between the layers of bulk 
$\mathrm{MoS}_{2}{ }^{8,13-16}$ This process starts first by reacting butyllithium with $\mathrm{MoS}_{2}$ to produce $\mathrm{Li}_{x} \mathrm{MoS}_{2}{ }^{13,16}$ Then, the resulting $\mathrm{Li}$ intercalated bulk $\mathrm{MoS}_{2}$ is immersed in water and sonicated to exfoliate it down to monolayer to few layer thick $\mathrm{MoS}_{2}$ nanosheets with dimensions typically of submicron lateral size. ${ }^{15,17,18}$ Whilst this method is attractive due its high yield of monolayer $\mathrm{MoS}_{2}$ sheets, it also has some major drawbacks; the process requires a long lithiation time (2-3 days) under reflux $\left(100{ }^{\circ} \mathrm{C}\right)$ conditions. ${ }^{13}{ }^{19}$ Furthermore, organolithium compounds are highly pyrophoric so must be handled away from oxygen and moisture, restricting the reaction to a glove box. ${ }^{20}$ In an attempt to simplify the synthetic procedure, some groups proposed a bottom-up approach using a hydrothermal process. ${ }^{11,21}$ According to their reports, this method can produce stable $1 \mathrm{~T}-\mathrm{MoS}_{2}$ in large quantities with a high concentration of metallic phase. This process, however, produces thicker $\mathrm{MoS}_{2}$ nanoplatelets and smaller flakes $(\sim 100 \mathrm{~nm}) .{ }^{11}$ Recently, Zhang et al. developed an electrochemical lithiation method for the synthesis of $1 \mathrm{~T}-\mathrm{MoS}_{2}{ }^{10}$ They prepared $\mathrm{MoS}_{2}$ electrodes by mixing the powder with carbon black $(10 \%)$ as a conducting additive and polyvinylidene fluoride (PVDF) as a binder (10\%), and then inserted it into a battery cell within an Ar-filled glove box using metallic lithium as a source of $\mathrm{Li}^{10,22}$ This method proved to be advantageous in terms of controlling the degree of lithium insertion as well as shortening the experimental time scale from days (as in chemical intercalation) to hours. Nonetheless, the use of metallic lithium restricts the intercalation process to controlled, inert atmosphere conditions. The battery-type electrochemical cell setup also presents challenges in terms of scale up. ${ }^{18}$ Furthermore, the conducting additive contaminated the exfoliated flakes and may have introduced side reactions during electrolysis. ${ }^{18}$

Herein, we report a simple and cost effective bench top experiment which eliminates the use of potentially explosive materials (such as metallic Li or organolithium compounds). $\mathrm{MoS}_{2}$ pellets (or $\mathrm{MoS}_{2}$ crystals) were used to demonstrate the principle of our approach. The pellet was made by pressing $\mathrm{MoS}_{2}$ powder without any conducting additives or polymer binder. Lithium salt was used as a source of Li and inert Pt mesh was used as a counter electrode so that the experiment can be carried out under ambient conditions without the need for a glove box. Electrochemical intercalation of $\mathrm{Li}^{+}$was conducted at a constant potential using 1.0 $\mathrm{M} \mathrm{LiClO}_{4}$ in a mixture of dimethyl carbonate (DMC) and ethylene carbonate $(E C)$ in an open beaker under a $N_{2}$ atmosphere. As the intercalated $\mathrm{MoS}_{2}$ was immersed in water, an instantaneous exfoliation was observed (see Video in supporting document). Characterisation of the exfoliated product was done using X-ray photoelectron spectroscopy, Raman spectroscopy and UV-visible absorption spectroscopy. This confirmed the formation of the 1Tphase with a concentration of $60 \%$. Significantly, atomic force microscopy (AFM) and Raman spectroscopy indicated that the majority of the flakes were trilayer in thickness. Finally, we show that the as-prepared material could be used as an efficient electrocatalyst for the hydrogen evolution reaction (HER) and as an electrode material for high performing coin cell supercapacitors.

\section{RESULTS AND DISCUSSION}

Cyclic voltammetry was used to determine the potential at which $\mathrm{Li}^{+}$ intercalation occurs into a $\mathrm{MoS}_{2}$ pellet: Figure 1 shows the cyclic voltammogram (CV) recorded at the $\mathrm{MoS}_{2}$ electrode in $0.1 \mathrm{M} \mathrm{LiClO}_{4}$ in DMC/EC mixture under $\mathrm{N}_{2}$ atmosphere. When the potential of the electrode was scanned in a negative direction, a cathodic current started to flow at approximately $-3.0 \mathrm{~V}$ vs. Ag wire, and a broad peak was observed between -4.5 to $-5.0 \mathrm{~V}$. This process was due to the insertion of $\mathrm{Li}^{+}$into the $\mathrm{MoS}_{2}{ }^{23,24}$ In the return sweep, a broad anodic peak was seen at $1.0 \mathrm{~V}$ due to the de-intercalation of $\mathrm{Li}^{+}$(Equation 1). The shape of the CV reported here is similar to that reported in the literature except that the peak-to-peak separation of the $\mathrm{Li}^{+}$intercalation and de-intercalation is wider. ${ }^{25} \mathrm{This}$ could be due to the differing geometry of the electrochemical cell (and scan rate) since we utilised a three electrode cell where the working and counter electrodes were separated by a few centimetres. In contrast, most studies used a two electrode cell in a battery-type (coin cell) configuration which then minimizes the voltage drop. ${ }^{24,26}$ As shown in Figure 1 , the formal potential of lithium intercalation/de-intercalation on a $\mathrm{Ag}$ wire pseudo reference scale is about -3.0 V whereas Chang et al reported a formal potential of $\sim 1.75 \mathrm{~V}$ for the same reaction on $\mathrm{L} \mathrm{Li}^{+} / \mathrm{Li}$ scale. ${ }^{24}$ This shows that the $\mathrm{Ag}$ wire reference electrode is at least $-4.75 \mathrm{~V}$ negative of $\mathrm{Li}^{+} / \mathrm{Li}$. Based on the CV result, $-4.5 \mathrm{~V}$ (vs. Ag) was chosen for electrochemical insertion of $\mathrm{Li}^{+}$into $\mathrm{MoS}_{2}$ since at this potential the insertion of $\mathrm{Li}^{+}$into $\mathrm{MoS}_{2}$ occurs at diffusion controlled rate. It has been shown that the stability of $\mathrm{Li}_{x}\left[\mathrm{MoS}_{2}\right]$ (where $x$ is in the range of $0 \leq x \leq 1)$ strongly depends on the applied potential during electrolysis. ${ }^{26-29}$. At extreme negative potentials $\left(<1.1 \mathrm{~V} \mathrm{vs.} \mathrm{Li}^{+} / \mathrm{Li}\right)$, below $-6.0 \mathrm{~V}$ vs $\mathrm{Ag}$ wire, decomposition of $\mathrm{Li}_{x}\left[\mathrm{MoS}_{2}\right]$ into $\mathrm{Mo}$ nanoparticles occurs, and conversion to $\mathrm{Li}_{2} \mathrm{~S}$ is the more favoured reaction. $^{26}$

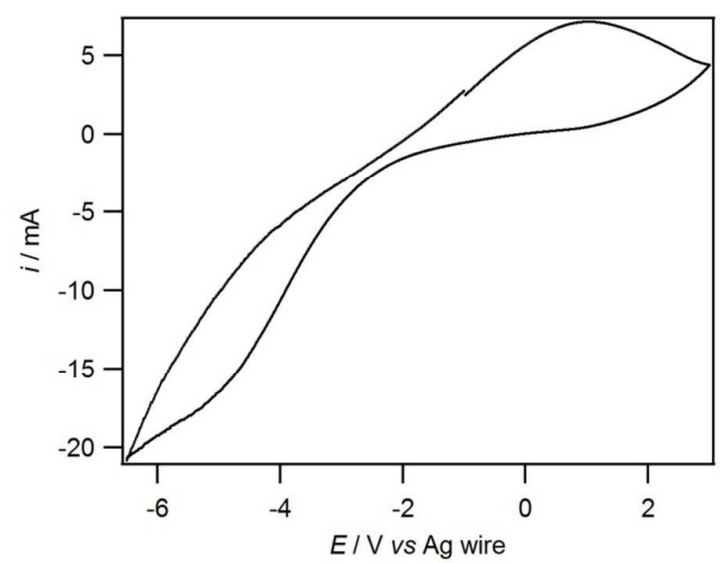

Figure 1. Cyclic voltammograms recorded at $\mathrm{MoS}_{2}$ electrode ( $\mathrm{MoS}_{2}$ pellet) in $0.1 \mathrm{M} \mathrm{LiClO}_{4}$ in EC:DMC (1:1) under $\mathrm{N}_{2}$ atmosphere. The potential was swept between 3.0 and $-6.5 \mathrm{~V}$ at $30 \mathrm{mV} \mathrm{s}^{-1}$.

Furthermore, excessive lithiation also leads to the decomposition reaction. ${ }^{30}$ We wish to note that, on the scale of our reference electrode, an applied potential between -4.0 and $-5.0 \mathrm{~V} v$ s. Ag wire did not result in any notable conversion reaction (see characterisation data below). Electrolysis was carried out for various time periods of $1 \mathrm{~h}, 2 \mathrm{~h}, 4 \mathrm{~h}$ and $6 \mathrm{~h}$ and the optimum electrolysis time was found to be $2 \mathrm{~h}$. At longer electrolysis time (> $2 \mathrm{~h}$ ), electrodeposition of $\mathrm{Li}^{+}$onto $\mathrm{MoS}_{2}$ occurs even if the $\mathrm{MoS}_{2}$ electrode was made porous (mixing $\mathrm{MoS}_{2}$ powder with PVDF and annealing at $450{ }^{\circ} \mathrm{C}$ under an $\mathrm{Ar}$ atmosphere) to facilitate Li-ion diffusivity. The optimum intercalation/exfoliation condition was obtained when thinner ( 1.0-1.5 mm thickness) $\mathrm{MoS}_{2}$ pellets were used and when no binder was added to the $\mathrm{MoS}_{2}$ powder. The $\mathrm{MoS}_{2}$ electrode showed slight expansion but not exfoliation during 
$\mathrm{Li}^{+}$intercalation process whereas in solvents like dimethyl sulfoxide; an instantaneous detachment of $\mathrm{MoS}_{2}$ electrode was observed before sufficient $\mathrm{Li}^{+}$intercalation occurred. The success of DMC/EC solvent system arises from the formation of solid electrolyte interface which prevents solvent co-intercalation. ${ }^{26}$ The $\mathrm{Li}^{+}$ intercalated $\mathrm{MoS}_{2}\left(\mathrm{Li}_{x}\left[\mathrm{MoS}_{2}\right]\right)$ pellet was then immersed into deoxygenated, deionised water and sonicated for $30 \mathrm{~min}$. During this process, a significant amount of gas evolution was noted due to the reaction between water and lithium which forms lithium hydroxide and hydrogen gas between the layers of $\mathrm{MoS}_{2}$ (Equation 2 and see video in $\mathrm{SI}$ ). The pressure of evolving hydrogen gas, catalysed by the $\mathrm{MoS}_{2}$, causes the exfoliation of the material. ${ }^{31}$

$\mathrm{MoS}_{2}+x \mathrm{Li}^{+}+x \mathrm{e}^{-} \leftrightarrow \mathrm{Li}_{x}\left[\mathrm{MoS}_{2}\right]$

$\mathrm{Li}_{x}\left[\mathrm{MoS}_{2}\right]+\mathrm{xH}_{2} \mathrm{O} \rightarrow \mathrm{MoS}_{2 \text { (nanosheet) }}+\mathrm{xLiOH}+0.5 \mathrm{xH}_{2}$

2.1 Characterization of the Exfoliated Product. Raman spectroscopy readily provides information on the phase of $\mathrm{MoS}_{2}$ and the thickness of the $\mathrm{MoS}_{2}$ flakes. The $2 \mathrm{H}$ and $1 \mathrm{~T}$ phase can easily be distinguished since each phase has different symmetry structures. ${ }^{31}$ Figure 2 shows the comparison between the Raman spectra of the raw $\mathrm{MoS}_{2}$ powder and the material after exfoliation by electrochemical intercalation of $\mathrm{Li}^{+}$. Two prominent Raman bands were observed in the bulk powder at $381.9 \mathrm{~cm}^{-1}$ and 407.4 $\mathrm{cm}^{-1}$ due to the in-plane vibration $\left(E_{2 \mathrm{~g}}^{1}\right)$ and the out-of-plane $\left(A_{1 \mathrm{~g}}\right)$ vibration respectively. ${ }^{32}$ After exfoliation, a series of extra Raman signatures emerged at $155 \mathrm{~cm}^{-1}\left(J_{1}\right), 227 \mathrm{~cm}^{-1}\left(J_{2}\right)$ and $330.5 \mathrm{~cm}^{-1}\left(J_{3}\right)$ in addition to the $E_{2 \mathrm{~g}}^{1}\left(382.2 \mathrm{~cm}^{-1}\right)$ and $A_{1 \mathrm{~g}}\left(405.3 \mathrm{~cm}^{-1}\right)$. These bands are the characteristic features for the formation of the $1 T$ phase. ${ }^{15,33}$ The formation of the 1T-phase in significant concentrations was also more evident by the major decrease in the intensity of the $E_{2 \mathrm{~g}}^{1}$ peak after exfoliation. ${ }^{33}$ Calandra suggested that $J_{1}$ was due to the in-plane shearing mode of one side of the $\mathrm{MoS}_{2}$ chain relative to the other, $J_{2}$ corresponds to the shifts of the $\mathrm{S}$-atom layers with respect to the Mo atoms and $J_{3}$ was due to the stretching of one side of the zig-zag chain relative to the other with a slightly out-of-plane component. ${ }^{34}$ The peak shape and position of $E_{2 \mathrm{~g}}^{1}$ and $A_{1 \mathrm{~g}}$ was also changed after exfoliation (Figure 2B). For example, the half width at half maximum of $A_{1 \mathrm{~g}}$ increased from 4.5 $\mathrm{cm}^{-1}$ in bulk $\mathrm{MoS}_{2}$ to $9.5 \mathrm{~cm}^{-1}$ after exfoliation and the peak separation between $E_{2 \mathrm{~g}}^{1}$ and $A_{1 \mathrm{~g}}$ decreased from $26 \mathrm{~cm}^{-1}$, in bulk $\mathrm{MoS}_{2}$, to $23.1 \mathrm{~cm}^{-1}$ in exfoliated samples. It has been reported in literature that the Raman spectrum of mechanically exfoliated $\mathrm{MoS}_{2}$ crystals exhibits a peak separation of $\sim 20, \sim 22$ and $\sim 23 \mathrm{~cm}^{-1}$ respectively for monolayer, bilayer and trilayer $\mathrm{MoS}_{2}$ nanosheets respectively. ${ }^{32,35}$ Based on this calibration data, the thickness of our exfoliated samples is therefore estimated to be trilayer.

The thickness of the exfoliated samples was further characterised by AFM and Figure $3 \mathrm{~A}$ shows the typical tapping mode AFM image of the exfoliated $\mathrm{MoS}_{2}$ flakes that were obtained from a $\mathrm{MoS}_{2}$ pellet. Statistical analysis of $150 \mathrm{MoS}_{2}$ flakes revealed that the majority of the lateral flake sizes vary between $300 \mathrm{~nm}$ and $500 \mathrm{~nm}$. However, it is possible to get lateral sizes over $2 \mu \mathrm{m}$ if the starting $\mathrm{MoS}_{2}$ material is a natural $\mathrm{MoS}_{2}$ crystallite (Figure 3B and $3 \mathrm{C})$, and this observation also the case when the flakes obtained from the two source were analysed by transmission electron microscopy (Figure S1).
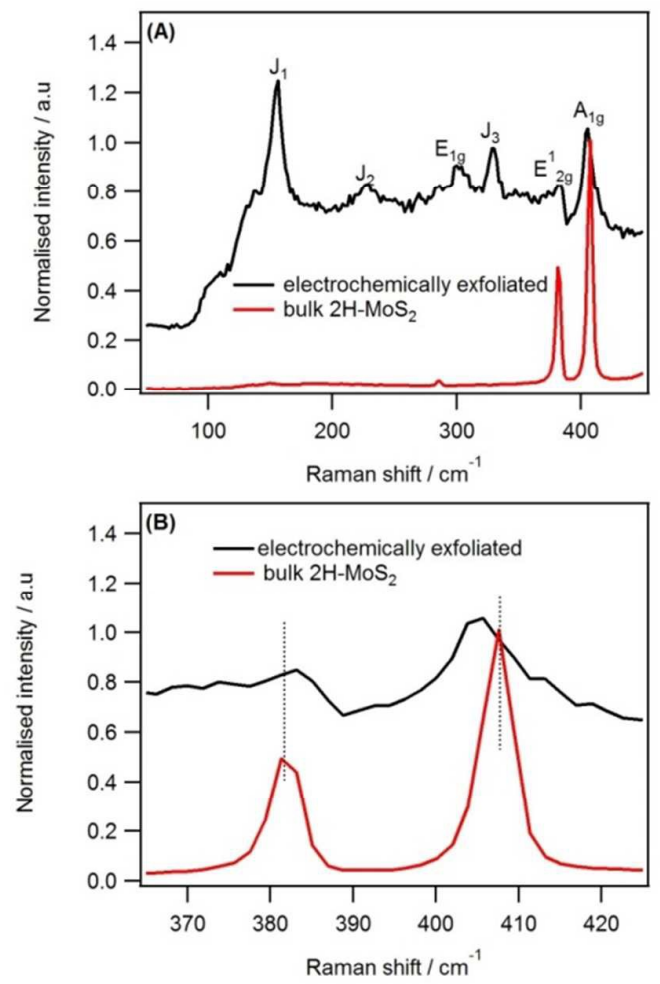

Figure $2(A)$ and (B) Raman spectra of electrochemically exfoliated $\mathrm{MoS}_{2}$ by intercalation of $\mathrm{Li}^{+}$. The electrochemical intercalation was performed at -4.5 $\mathrm{V}$ vs $\mathrm{Ag}$ wire from a solution containing $1.0 \mathrm{M} \mathrm{LiClO}_{4}$ in $\mathrm{DMC} / \mathrm{EC}$. The sample for Raman analysis was prepared by drop coating the dispersion of $\mathrm{MoS}_{2}$ on to $\mathrm{Si} / \mathrm{SiO}_{2}$ wafer which was then dried in air at room temperature

Remarkably the majority (>95\%) of the flake thicknesses displayed the same topographic height of $4.5 \mathrm{~nm}$ regardless of the source of $\mathrm{MoS}_{2}$ used for exfoliation ( $\mathrm{MoS}_{2}$ powder or crystalline). Previous works showed that the measured flake thicknesses for solution/chemically exfoliated $\mathrm{MoS}_{2}$ deposited on $\mathrm{Si} / \mathrm{SiO}_{2}$ varied between 1.1 and $1.9 \mathrm{~nm}$ for monolayer and $\sim 5 \mathrm{~nm}$ for trilayer nanosheets. ${ }^{15,36}$ The deviations from their theoretical thickness (0.615 $\mathrm{nm}$ for monolayer) were attributed to the presence of adventitious adsorbates, trapped or adsorbed water molecules and flake-substrate equilibrium separation. ${ }^{15,35}$ In the case of $1 \mathrm{~T}$ phase in particular, the excess negative charge formed due to the electron donation from lithium is stabilised by adsorption of water molecules on both sides of the nanosheets which then increases the overall thickness of the flake. ${ }^{11,17}$ The presence of adsorbed water layers on $1 \mathrm{~T}-\mathrm{MoS}_{2}$ is supported using powder X-dray diffraction data which shows a diffraction peak at $2 \theta \approx 8^{\circ}$ that was not present in bulk $\mathrm{MoS}_{2}$ (Figure S2) and the corresponding d-spacing is $1.1 \mathrm{~nm}$. Previous work attributed this process to the adsorption of bilayer water molecules between the adjacent layers of $\mathrm{MoS}_{2}$ nanosheets. $17 \mathrm{~A}$ broad diffraction peak also seen at $14.5^{\circ}(002)$ with interlayer distance of $6.1 \mathrm{~nm}$, and no other peaks were observed unlike in bulk $\mathrm{MoS}_{2}$. We should also note that a few flakes showed a 
thickness of $1.5 \mathrm{~nm}$ which are probably monolayer $\mathrm{MoS}_{2}$ (Figure 3D pink line). The thickness of a monolayer of water molecules
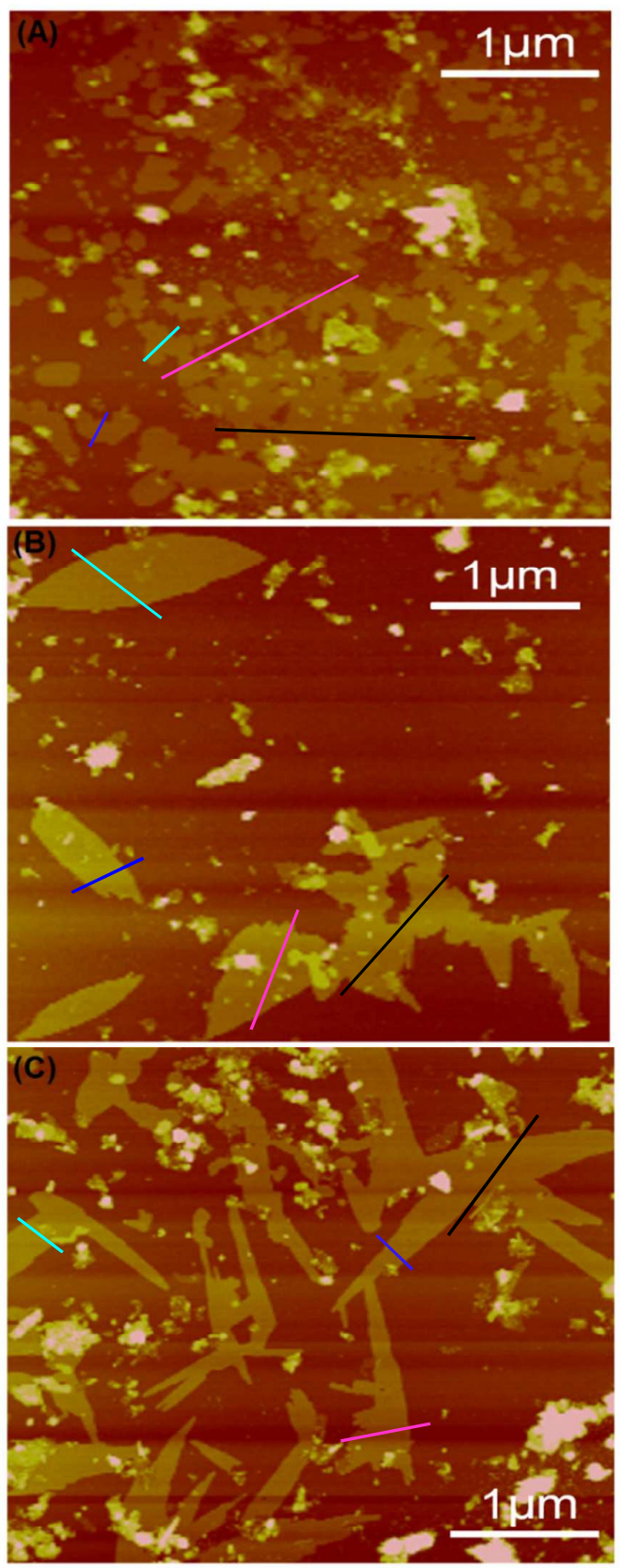
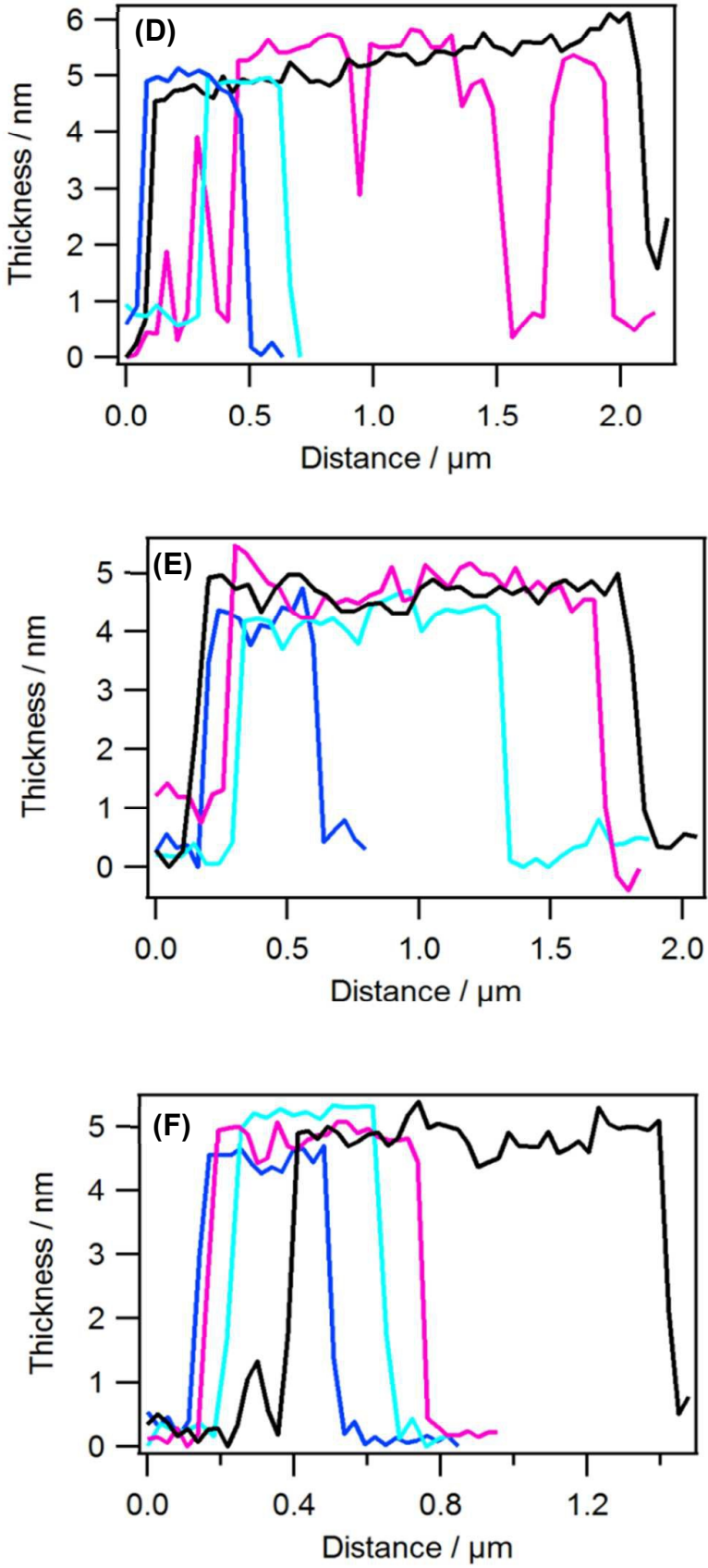

Figure $3 \mathrm{AFM}$ images of $\mathrm{MoS}_{2}$ flakes that were obtained by electrochemical intercalation of $\mathrm{Li}^{+}$at $-4.5 \mathrm{~V}$ vs $\mathrm{Ag}$ wire for $2 \mathrm{~h}$ in $1.0 \mathrm{M}$ LiClO 4 in DMC/EC. The samples were prepared by spray coating $\mathrm{Si} / \mathrm{SiO}_{2}$ wafer from dilute dispersion of $1 \mathrm{~T}-\mathrm{MoS}_{2}(\mathrm{~A})$ obtained from $\mathrm{MoS}_{2}$ pellet and (B) and (C) obtained from MoS 2 natural crystal. (D), (E) and $(F)$ show the corresponding thickness of the selected flakes for $(A),(B)$ and $(C)$ respectively 

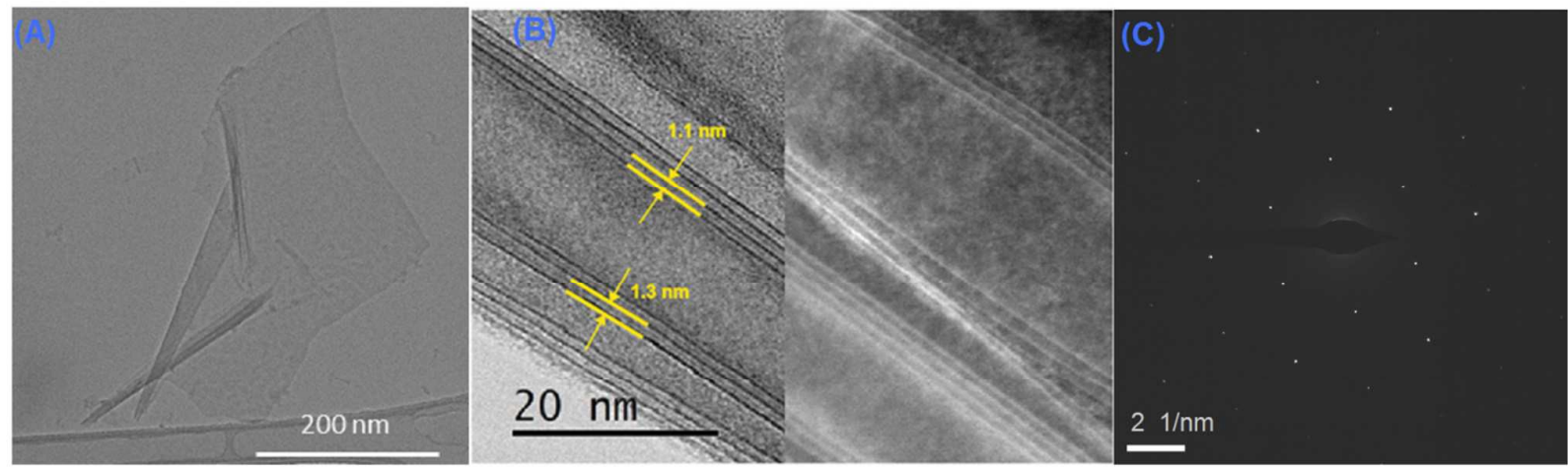

Figure 4. (A) TEM image of $\mathrm{MoS}_{2}$ flakes that were obtained by electrochemical intercalation of $\mathrm{Li}^{+}$at $-4.5 \mathrm{~V}$ vs $\mathrm{Ag}$ wire for $2 \mathrm{~h}$ in $1.0 \mathrm{M} \mathrm{LiClO}{ }_{4}$ in $\mathrm{DMC} / \mathrm{EC}$ (B) high resolution TEM image collected in bright field (left) and dark field (right) showing predominately trilayer $\mathrm{MoS}_{2}$ nanosheets and (C) the diffraction pattern obtained from trilayer $\mathrm{MoS}_{2}$ flake.

was estimated as $0.26 \mathrm{~nm}^{17}$. Therefore, the thickness of a monolayer of $\mathrm{MoS}_{2}$ covered with a bilayer of water molecules would equal $1.14 \mathrm{~nm}$ - similar to the interlayer spacing measured using XRD. The flake thickness and its diffraction pattern was also analysed by high resolution TEM. The majority of the flakes analysed formed trilayer $\mathrm{MoS}_{2}$ nanosheets although there are some monolayer, bilayer, and multilayers $(\geq 4)$ structures (see Figure 4B and Figure S3). It is interesting to note that the interlayer spacing of the nanosheets was consistently between $1.1 \mathrm{~nm}$ and $1.3 \mathrm{~nm}$ in agreement with XRD and AFM analysis. The diffraction pattern of the trilayer nanosheets also shows the typical crystalline hexagonal $\mathrm{MoS}_{2}$ structure which is similar to the diffraction pattern reported for chemically exfoliated $1 \mathrm{~T}-\mathrm{MoS}_{2}{ }^{37}$ Analysis of our Raman data in conjunction with AFM thickness measurement and TEM flake layers analysis strongly suggests that the majority of the flakes are trilayer. It has been widely acknowledged that the chemical intercalation of $\mathrm{MoS}_{2}$ with butyllithium in stoichiometric amounts usually produces monolayer $\mathrm{MoS}_{2}{ }^{15,31}$ The fact that we obtained trilayer $\mathrm{MoS}_{2}$ sheets demonstrated that the intercalation of $\mathrm{Li}^{+}$is at a less than stoichiometric ratio. One of the interesting aspects of electrochemical intercalation over chemical intercalation is that we can determine the amount of lithium inserted during electrolysis. The number of moles of $\mathrm{Li}^{+}$transferred was obtained by measuring the charge passed during electrolysis; this was then related to the number of moles of $\mathrm{MoS}_{2}$ used for intercalation to calculate the value of $x$ in $\mathrm{Li}_{x} \mathrm{MoS}_{2}$. We obtained $x=0.75$ which confirms the substoichiometric intercalation of $\mathrm{Li}^{+}$, and that the preferential exfoliation of $\mathrm{MoS}_{2}$ to trilayer might be due to a staged intercalation process. Recent work by Fan et al. also showed that the chemical intercalation of butyllithium in sub-stoichiometry into $\mathrm{MoS}_{2}$ produces trilayer nanosheets, and the authors attributed this to the formation of stage $3 \mathrm{Li}$ intercalation where each Li inserts between three layers of $\mathrm{MoS}_{2}{ }^{36}$

Figure 5 shows the UV-Visible absorption spectra of 1T-MoS and $2 \mathrm{H}-\mathrm{MoS}_{2}$ dispersion (diluted in isopropanol). It is known that the $2 \mathrm{H}$ phase is semiconducting and therefore exhibits characteristic excitonic peaks that are related to its band gap. The dispersion obtained from the $2 \mathrm{H}$ phase showed two notable excitons at $604 \mathrm{~nm}$ and $667 \mathrm{~nm}$ that were associated with the direct-gap transition due to the energy split from valence band and spin-orbit coupling. ${ }^{38,39}$ After exfoliation, the two excitonic peaks (A and B) disappeared due to the phase transition from the semiconducting to metallic $\mathrm{MoS}_{2}$ : this observation is consistent with previous reports. $^{10,15}$ The difference in optical properties is also more evident when examining the colour of the respective phase dispersions where the $2 \mathrm{H}$ phase is dark yellow while the $1 \mathrm{~T}-\mathrm{MoS}_{2}$ is dark grey.

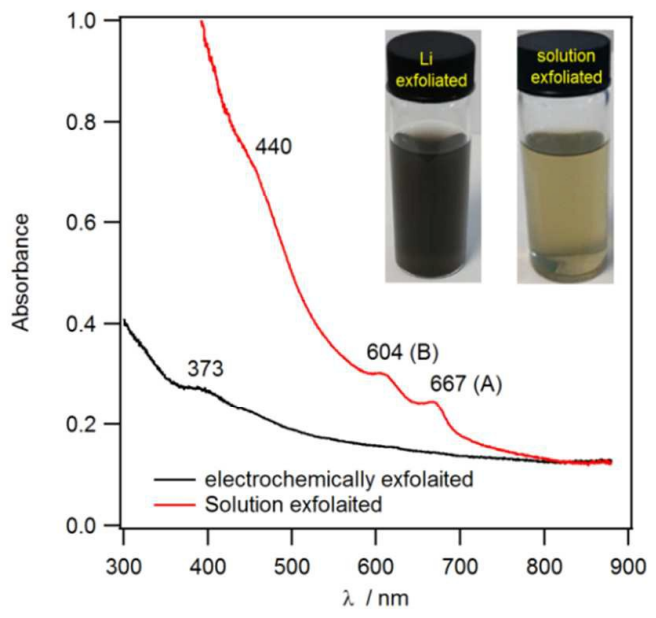

Figure 5 Optical absorption spectrum of $\mathrm{MoS}_{2}$ dispersion in water and isopropanol (1:1) mixture. The inset picture shows the dispersion of electrochemically exfoliated $\mathrm{MoS}_{2}$ by Li intercalation and solution exfoliated by sonication

It has been shown that the complete phase transformation from $2 \mathrm{H}$ to $1 \mathrm{~T}$ has never been realised using lithium intercalation 

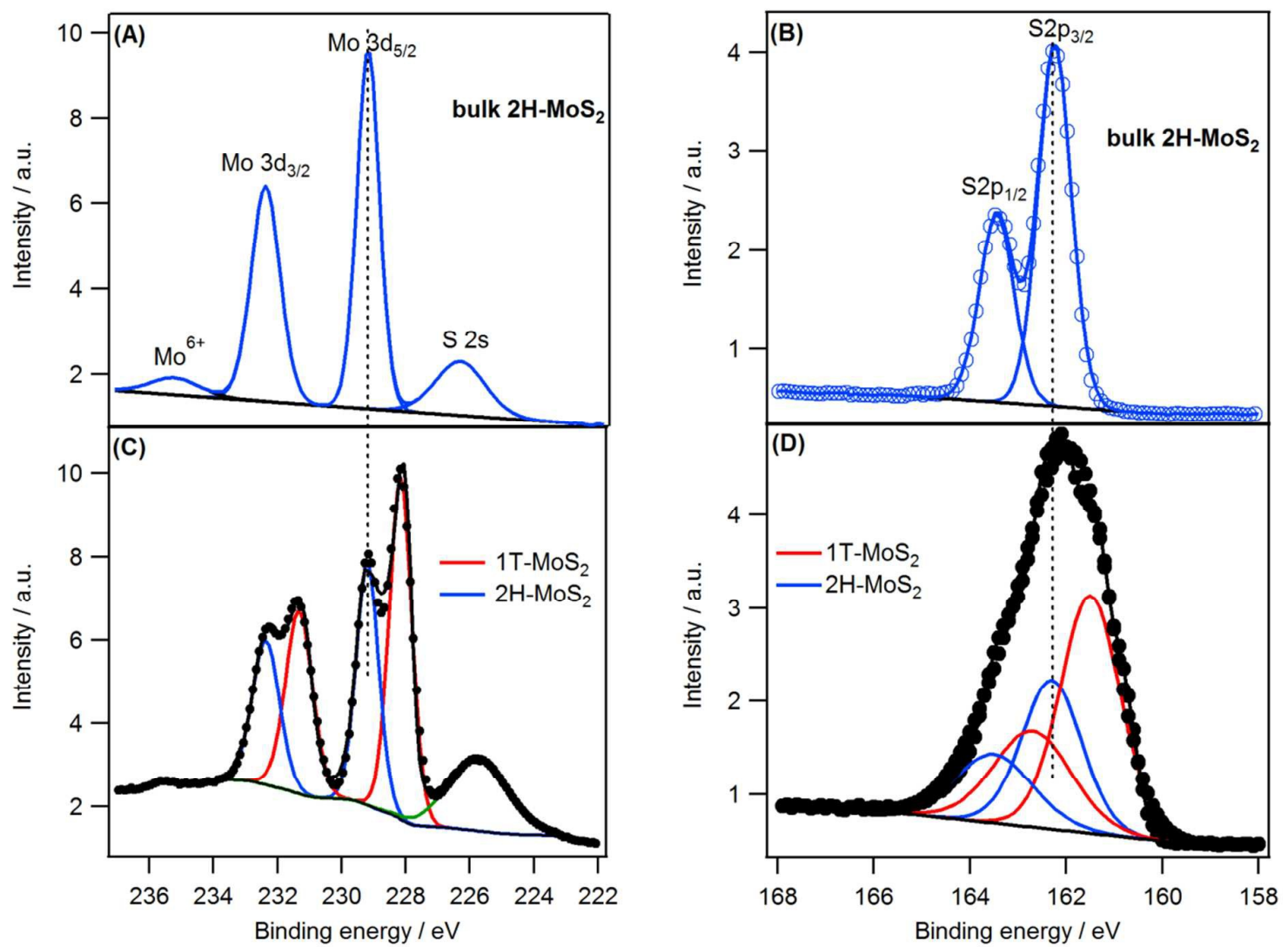

Figure 6 (A)High-resolution XP spectrum of bulk $\mathrm{MoS}_{2}$ in the Mo3d region, (B) High-resolution XP spectrum of bulk MoS in the S2p region, (C) Highresolution XP spectrum of electrochemically exfoliated $\mathrm{MoS}_{2}$ by intercalation of $\mathrm{Li}^{+}$in the Mo3d region and (D) High-resolution XP spectrum of electrochemically exfoliated $\mathrm{MoS}_{2}$ by intercalation of $\mathrm{Li}^{+}$in the $\mathrm{S} 2 \mathrm{p}$ region. All peak positions were charge-corrected by setting the binding energy of the $\mathrm{C}$ 1s signal to $284.5 \mathrm{eV}$. The samples for XPS were prepared by filtering the dispersions onto a PVDF membrane
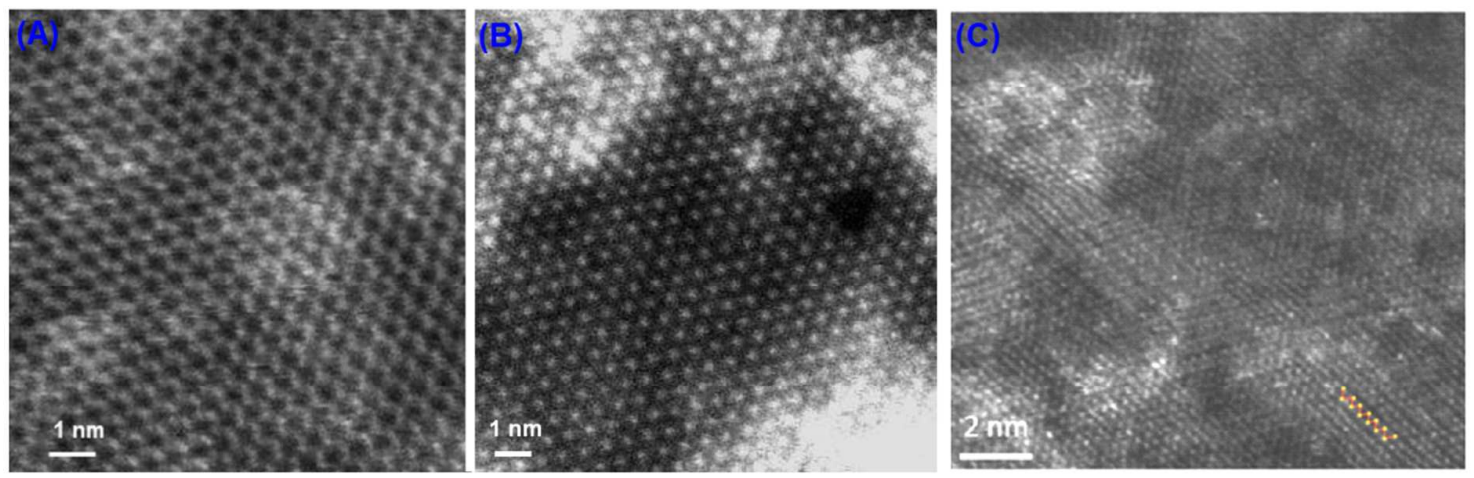

Figure 7. High angle annular dark-field scanning transmission electron microscopy of electrochemically exfoliated MoS 2 showing (A) $2 \mathrm{H}$ phase collected from multilayer region, (B) 1T phase from monolayer $\mathrm{MoS}_{2}$ and (C) 1T' phase from MoS . The yellow balls and red lines in inset of (C) indicate the zigzag chain of $1 T^{\prime}$ superlattice. 
and often the resulting structures contain a portion of both $2 \mathrm{H}$ and $1 \mathrm{~T}$ phases. ${ }^{15,40}$ XPS was used to quantify the fraction of each phase by the deconvolution of the high resolution spectra of the Mo3d and S2p peaks and Figure 6 shows the XPS spectra of the bulk and exfoliated $\mathrm{MoS}_{2}$. The Mo 3d spectra of bulk $2 \mathrm{H}-\mathrm{MoS}_{2}$ displayed a doublet with peaks at $229.2 \mathrm{eV}$ and $232.4 \mathrm{eV}$ that correspond to $\mathrm{Mo}^{4+} 3 \mathrm{~d}_{5 / 2}$ and $\mathrm{Mo}^{4+} 3 \mathrm{~d}_{3 / 2}$, respectively. After exfoliation, a new pair of peaks emerged, in addition to the known doublet peak of $\mathrm{Mo}^{4+}$ for $2 \mathrm{H}-\mathrm{MoS}_{2}$, that are shifted to lower binding energies by $\sim 0.8 \mathrm{eV}$ with respect to the $2 \mathrm{H}$ phase. Similarly, the S2p doublet also displayed a new pair of peaks at a lower binding energy of $161.5 \mathrm{eV}$ $\left(\mathrm{S} 2 \mathrm{p}_{3 / 2}\right)$ and $162.7 \mathrm{eV}\left(\mathrm{S} 2 \mathrm{p}_{1 / 2}\right)$. These new pairs of peaks were due to the formation of the $1 T$ phase. ${ }^{15,40}$ Deconvolution of the Mo $3 d$ and $S 2 p$ regions indicates that the concentration of $1 T$ phase in the nanosheets is $60 \%$. The concentration of the $1 T$ phase using chemical exfoliation yields between 60 to $70 \%$, which is in close agreement with our exfoliation method. ${ }^{7,41}$

The structural change from the $2 \mathrm{H}$ to $1 \mathrm{~T}$ phase is attributed to the electron donation from lithium into the conduction band of $\mathrm{MoS}_{2}{ }^{31,40}$ The unoccupied (4d) conduction band states in the Mo cations of the $\mathrm{MoS}_{2}$ are lower in energy than the occupied valence electron states of lithium atoms. ${ }^{26,40}$ Electron transfer from lithium atoms to the unoccupied $4 \mathrm{~d}$ orbitals occurs easily upon intercalation so that the resulting $\mathrm{MoS}_{2}$ structure assumes a metallic nature. It has been suggested that the content of Li within the $\mathrm{MoS}_{2}$ structures determines the most favourable phase of molybdenum disulphide. For example, when $x \leq 0.1$ (as in $\mathrm{Li}_{x} \mathrm{MoS}_{2}$ structure) the intercalation proceeds without disruption of the $2 \mathrm{H}$ phase. However, as the concentration of $\mathrm{Li}$ increases above $x=0.1$ within the $2 \mathrm{H}-\mathrm{MoS}_{2}$ lattice, the distorted octahedral structure becomes more stable. ${ }^{42}$

The analysis of the XPS data showed that the exfoliated samples contained both the $2 \mathrm{H}$ and $1 \mathrm{~T}-\mathrm{MoS}_{2}$ structures. High angle annular dark-field scanning transmission electron microscopy (HAADF-STEM) was conducted on the exfoliated samples to gain further insight into the atomic structure. Figure 7 shows the high resolution HAADF STEM images of electrochemically exfoliated $\mathrm{MoS}_{2}$ nanosheets. As expected the analysed flakes comprised of regions of $2 \mathrm{H}$ phase, the $1 \mathrm{~T}$ phase and the distorted $1 \mathrm{~T}$ phase $\left(1 \mathrm{~T}^{\prime}\right)$ which is in agreement with chemically exfoliated $1 \mathrm{~T}-\mathrm{MoS}_{2}{ }^{37}{ }^{37}$ It has been suggested that the electron transfer from lithium into $\mathrm{MoS}_{2}$ during intercalation, leads to structural destabilization from the ideal 1T structure. ${ }^{31,37}$ The Mo atoms undergo structural distortion, reducing the inter-atomic spacing which results in the formation of a characteristic zig-zag pattern (inset of Figure 7C).

\subsection{Electrochemical Application of the Exfoliated 1T-MoS 2}

2.2.1 Hydrogen Evolution Reaction at 1T-MoS . To date, Pt-based materials are the most efficient and durable electrocatalysts for electrochemical $\mathrm{H}_{2}$ generation. ${ }^{43}$ Since $\mathrm{Pt}$ is scarce and expensive, intense research efforts have been made by the scientific community to find alternative, cheaper electrocatalysts. Transition metal dichalcogenides in general and molybdenum disulphide in particular, have recently emerged as a promising class of materials for HER electrocatalysis. ${ }^{44,45}$ Experimental and computational results indicated that the metallic edge (sulfideterminated Mo-edge) structures of $2 \mathrm{H}-\mathrm{MoS}_{2}$ crystals are the active site for HER while its basal plane remains inert towards HER because of its poor electrical conductivity. ${ }^{46}$ Although intense studies focused on surface structure engineering of $2 \mathrm{H}-\mathrm{MoS}_{2}$ to increase the percentage of active edge sites, ${ }^{47-49}$ the overall performance of $2 \mathrm{H}-\mathrm{MoS}_{2}$ is still limited by inefficient charge transfer and poor electrical transport between the active sites and the basal plane.

The electrocatalytic activity of our electrochemically exfoliated $1 \mathrm{~T}-\mathrm{MoS}_{2}$ towards HER was assessed using linear sweep voltammetry and electrochemical impedance spectroscopy using a three electrode configuration in deoxygenated $0.5 \mathrm{M} \mathrm{H}_{2} \mathrm{SO}_{4}$ (aq). The electrodes were prepared by drop-coating a suspension of 1T$\mathrm{MoS}_{2}$ onto glassy carbon electrodes to a mass loading of $12 \mu \mathrm{g} \mathrm{cm}$. Figure $8 \mathrm{~A}$ shows the polarisation curve obtained at $\mathrm{Pt}, 2 \mathrm{H}-\mathrm{MoS}_{2}$ and $1 \mathrm{~T}-\mathrm{MoS}_{2}$ electrocatalysts. In each case the current densities are normalized to the geometric area of each electrode and the data was corrected for $i R$ (ohmic) drop. The $2 \mathrm{H}$ phase displayed an overpotential $(\eta)$ of $\sim 0.25 \mathrm{~V}$ and reasonable current density (10 $\mathrm{mA} \mathrm{cm}{ }^{-2}$ ) was only seen when $\eta$ exceeded $0.35 \mathrm{~V}$. The low catalytic activity for HER is presumably due to the small proportion of the active edge sites as well as poor electrical transport between the active site and the basal plane. In particular, for $2 \mathrm{D} 2 \mathrm{H}-\mathrm{MoS}_{2}$ nanosheets, the portion of the inert basal plane is significantly larger than its edge site; this then leads to the low HER electrocatalytic current. However, the 1T phase exhibited low $\eta$ of $0.13 \mathrm{~V}$ with substantial improvement in electrocatalytic current density (for example, $50 \mathrm{~mA} \mathrm{~cm}{ }^{-2}$ recorded at $\eta=0.23 \mathrm{~V}$ ), this observation correlates well with previously reported data. ${ }^{8,9}$ Voiry et al. ${ }^{9}$ have studied the HER using the chemically exfoliated $1 T$ $\mathrm{MoS}_{2}$ electrocatalyst, and observed an HER overpotential of approximately $0.25 \mathrm{~V}$ at a current density of $\sim 30 \mathrm{~mA} \mathrm{~cm}^{-2}$. Their work also suggested that, unlike $2 \mathrm{H}-\mathrm{MoS}_{2}$ where the basal plane is catalytically inert towards HER, the basal plane of $1 \mathrm{~T}-\mathrm{MOS}_{2}$ is the main active site for HER, which explains the high current density measured for the $1 T$-phase. ${ }^{9}$ The reactivity of the $1 T$ phase basal plane has also been suggested by recent density functional theory work, which indicates that the basal plane at the surface sulfur sites acts as the binding site for the hydrogen atom. ${ }^{12}$

The measured Tafel slopes for Pt, 1T and 2H phase $\mathrm{MoS}_{2}$ are 33, 49 , and $109 \mathrm{mV}$ decade $^{-1}$ (Figure $8 \mathrm{~B}$ ) respectively, these values are consistent with previous studies. ${ }^{8,9}$ The proposed general models ${ }^{50,51}$ for HER suggest that the Tafel plot should have a slope of $118 \mathrm{mV}$ decade ${ }^{-1}$ at $25^{\circ} \mathrm{C}$ if the adsorption of hydrogen atoms (the Volmer step, Equation 3 ) is the rate-determining step:

$\mathrm{H}^{+}+\mathrm{e}^{-} \rightarrow \mathrm{H}_{\mathrm{ad}}$

The Volmer step may be followed by an electrochemical desorption step, or two adsorbed $\mathrm{H}$ atoms can combine and desorb:

$\mathrm{H}_{\mathrm{ad}}+\mathrm{H}^{+}+\mathrm{e}^{-} \rightarrow \mathrm{H}_{2}$

$\mathrm{H}_{\mathrm{ad}}+\mathrm{H}_{\mathrm{ad}} \rightarrow \mathrm{H}_{2}$

where Equations 4 and 5 are the Heyrovsky and Tafel steps, respectively.

If the Heyrovsky or Tafel steps are rate determining, the Tafel slope should be about $40 \mathrm{mV}$ decade ${ }^{-1}$ and $30 \mathrm{mV}$ decade $^{-1}$, respectively. Therefore, our data suggest that the rate of the HER at the 1T phase electrocatalyst is controlled by the Volmer-Heyrovsky step while at the $2 \mathrm{H}$-phase the Volmer step is the rate determining. The electrocatalytic activity of the $1 \mathrm{~T}$ and $2 \mathrm{H}$ phases were also further examined by electrochemical impendence spectroscopy at $\eta=0.25$ $\mathrm{V}$ vs. RHE. Figure $8 \mathrm{C}$ shows the resulting Nyquist plots fitted to an 
equivalent circuit that contains solution resistance $\left(R_{\mathrm{S}}\right)$, a constant phase element (CPE) and a charge transfer resistance $\left(R_{\mathrm{CT}}\right)$ as shown
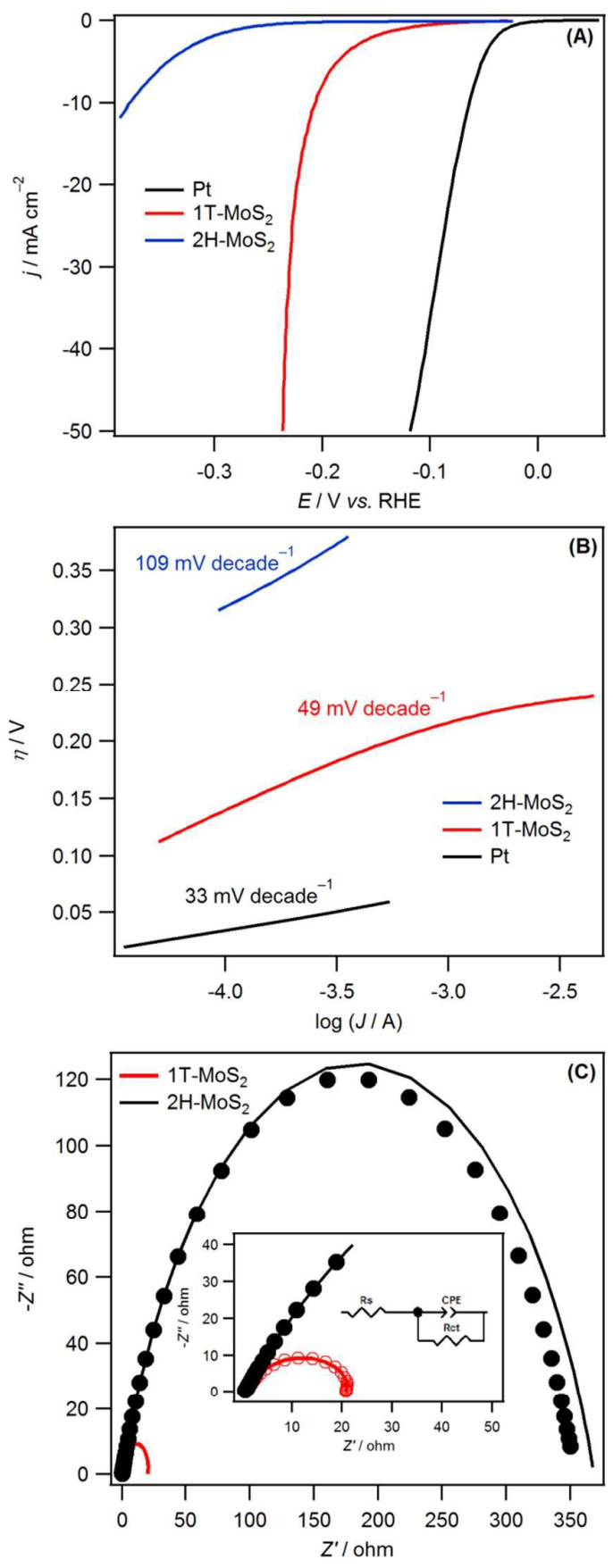

Figure $8(\mathrm{~A})$ polarization curve recorded in deoxygenated $0.5 \mathrm{M} \mathrm{H}_{2} \mathrm{SO}_{4}(\mathrm{aq})$ at indicated electrodes between $0.0 \mathrm{~V}$ to $-0.4 \mathrm{~V}$. (B) Tafel plot (log of current versus overpotential) generated from the polarisation curve shown in (A), (C) Nyquist plots obtained in deoxygenated $0.5 \mathrm{M} \mathrm{H}_{2} \mathrm{SO}_{4}(\mathrm{aq})$ at a $2 \mathrm{H}-\mathrm{MoS}_{2}$ and $1 \mathrm{~T}-\mathrm{MoS}_{2}$ electrode in a three-electrode cell. The measurements were carried out at an oscillation amplitude of $5 \mathrm{mV}$ in the frequency range 100 $\mathrm{mHz}$ to $100 \mathrm{KHz}$, at an applied potential of $-0.25 \mathrm{~V} v \mathrm{~s}$. RHE. The solid lines show the experimental data and the markers show theoretical fits generated using the equivalent circuit shown (inset). in the inset of Figure 8C. The Nyquist plots show one semicircle due to the $R_{C T}$ of HER. From the best fits of the data to the equivalent circuit, values for $R_{\mathrm{CT}}$ at each electrocatalyst were obtained. For the $2 \mathrm{H}$ phase the $R_{\mathrm{CT}}$ of HER was $320 \Omega \mathrm{cm}^{2}$, this value decreased to 20 $\Omega \mathrm{cm}^{2}$ with the $1 T$ phase. The trend in the $R_{\mathrm{CT}}$ values shows that charge transfer was significantly faster at the $1 \mathrm{~T}-\mathrm{MoS}_{2}$ surface than at the $2 \mathrm{H}-\mathrm{MoS}_{2}$, which is consistent with the linear sweep voltammogram data.

2.2.2 Electrode Material for Supercapacitors. Chhowalla et al. recently showed that the gravimetric capacitance of a cell constructed using chemically exfoliated $1 \mathrm{~T}-\mathrm{MoS}_{2}$ was up to 20 times higher than a cell constructed using pure $2 \mathrm{H}-\mathrm{MoS}_{2} .{ }^{7}$ The enhancement in capacitance seen for the former cell was attributed to its high electrical conductivity, high hydrophilicity and its ability to intercalate various ions. ${ }^{7}$ Their work also showed that the cation intercalation process is the dominant charge storage mechanism at this novel electrode. ${ }^{7}$ We also tested the capacitance of our electrochemically exfoliated $1 \mathrm{~T}-\mathrm{MoS}_{2}$ in symmetrical coin cells via the cyclic voltammetric (CV) and galvanostatic charge-discharge response. The $\mathrm{CVs}$ obtained using electrodes made from the $2 \mathrm{H}$ phase displayed a gravimetric capacitance of $6 \mathrm{~F} \mathrm{~g}^{-1}$ whereas the $1 T$ phase displayed a gravimetric capacitance of $102 \mathrm{~F} \mathrm{~g}^{-1}$ at $10 \mathrm{mV} \mathrm{s}^{-1}$ (Figure 9A) which are consistent with previous reports. ${ }^{7,52}$ The capacitance of the $1 T$ phase was found to be strongly dependent on the potential scan rate: at $5 \mathrm{mV} \mathrm{s}^{-1}$ the gravimetric capacitance was $114 \mathrm{~F} \mathrm{~g}^{-1}$ and this value decreased almost by half, to $59 \mathrm{~F} \mathrm{~g}^{-1}$, on increasing the scan rate to $100 \mathrm{mV} \mathrm{s}^{-1}$ (Figure 9B). Similarly, the capacitance obtained from the charge-discharge curve also showed an analogous trend to the $\mathrm{CV}$ data where the capacitance decreased from $118 \mathrm{~F} \mathrm{~g}^{-1}$ at $0.5 \mathrm{~A} \mathrm{~g}^{-1}$ to $50 \mathrm{~F} \mathrm{~g}^{-1}$ at $5 \mathrm{~A} \mathrm{~g}^{-1}$. The decrease in capacitance upon increasing scan rate $(v)$ or discharge current might be associated with the effect of ion diffusion as well as with the resistivity of the electrode. In particular, when the charge storage mechanism involves ion intercalation, the effect of ion diffusion into layered $\mathrm{MoS}_{2}$ structure becomes more pronounced. For example, the experimental time scale could be too short to intercalate ions into the layered structures at high $v$ which then accounts for the low capacitance. The internal resistance of the device also contributes to the decrease in capacitance. The effect of resistance is more apparent when examining the charge-discharge curve. As shown in Figure 9D, the discharge curve shows a significant voltage drop $(>0.3 \mathrm{~V})$ for the cell that was constructed using $1 \mathrm{~T}-\mathrm{MoS}_{2}$. Therefore, increasing the conductivity of the electrode, by adding highly conductive graphene, is expected to enhance the capacitance at higher discharge currents. Herein, we fabricate a nanocomposite that consists of $1 \mathrm{~T}-\mathrm{MoS}_{2}$ and solution exfoliated graphene (SEG) to alleviate these problems. The composite was made by mixing 1T$\mathrm{MoS}_{2}$ with SEG in a one to one concentration ratio and the SEM image of the membrane shows a randomly restacked layered structure (Figure 10E and 10F). The morphology of the composite material looks more interconnected porous and rougher surface than the individual components (Figure S4). Furthermore, the SEM image of pure graphene or $\mathrm{MoS}_{2}$ shows an aggregated nanosheet. Figure $9 \mathrm{E}$ shows a representative Raman spectrum taken from the composite membrane. The spectrum shows the characteristic 1T$\mathrm{MoS}_{2}$ peaks and graphene peaks demonstrating that the two materials are uniformly mixed and distributed across the membrane. Moreover, the presence of graphene with $1 \mathrm{~T}-\mathrm{MoS}_{2}$ in the composite did not induce a phase transition. 
The electrodes made from the composite materials displayed typical capacitive behaviour with a nearly rectangular shape and the charge-discharge curve also displayed a symmetrical linear shape with voltage drop of less than $0.1 \mathrm{~V}$ (Figure 9A and 9C). Significantly, 1T-MoS $/$ graphene electrode showed an enhanced gravimetric capacitance with little loss as the discharge current increased. For example, the composite material displayed a capacitance of $147 \mathrm{~F} \mathrm{~g}^{-1}$ at $10 \mathrm{mV} \mathrm{s}^{-1}$ and $120 \mathrm{~F} \mathrm{~g}^{-1}$ at $100 \mathrm{mV} \mathrm{s}^{-1}$ (Figure 9B). The enhanced capacitance in the composite material was probably due to the synergistic effect between $1 \mathrm{~T}-\mathrm{MoS}_{2}$ and graphene where graphene enhances the overall conductivity of the composite, reduces the re-aggregation of the sheets and partly contribute double layer capacitance while 1T-MoS 2 contribute pseudocapacitance through ion intercalation. ${ }^{52}$ Indeed, the nanocomposite dispersion showed stability without any substantial sedimentation over two month whilst the $1 \mathrm{~T}-\mathrm{MoS}_{2}$ dispersion completely aggregated over the same period of time (Figure S6) which indicates that graphene plays a role in hindering the aggregation of $\mathrm{MoS}_{2}$. This synergy was also evident when comparing the gravimetric capacitance of pure graphene which only produced $18 \mathrm{~F} \mathrm{~g}^{-1}$ with that of the composite.
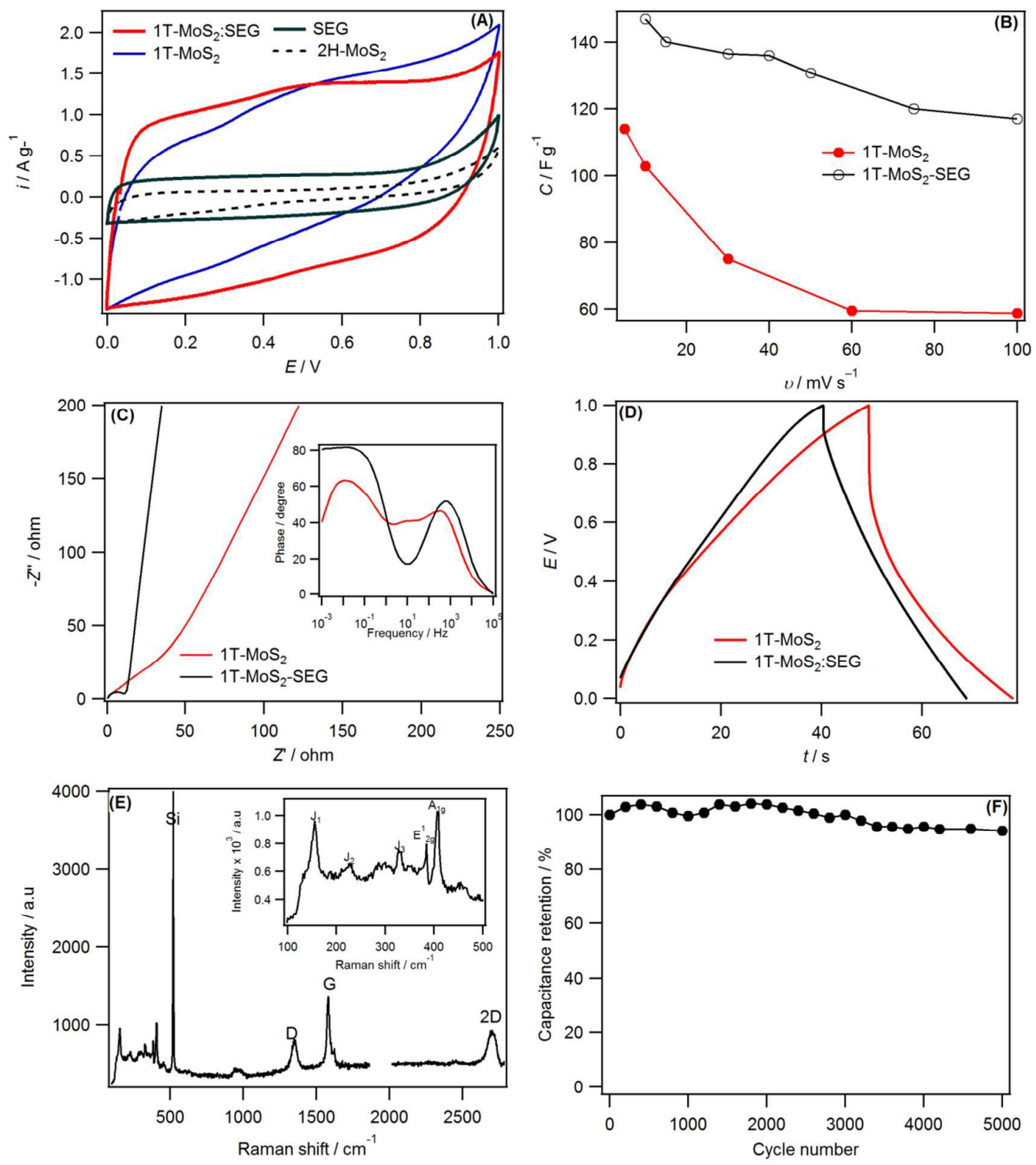

Figure 9 (A) Cyclic voltammograms recorded at $20 \mathrm{mV} \mathrm{s}^{-1}$ in $6.0 \mathrm{M} \mathrm{KOH} \mathrm{(aq)} \mathrm{using} \mathrm{symmetrical} \mathrm{coin} \mathrm{cells} \mathrm{constructed} \mathrm{from} \mathrm{indicated} \mathrm{electrodes.} \mathrm{(SEG}$ denotes solution exfoliated graphene). The voltage was scanned between $0.0 \mathrm{~V}$ (initial potential) and $1.0 \mathrm{~V}$, (B) Gravimetric capacitance as a function of scan rates at indicated electrodes, $(C)$ Nyquist plots obtained using the coin cells at shown electrodes and the inset shows the Bode plot. The measurements were carried out at an amplitude of $5 \mathrm{mV}$ in the frequency range of $100 \mathrm{mHz}$ to $100 \mathrm{KHz}$ at open circuit potential. (D) Charge-discharge curve obtained from indicated electrodes at $1.0 \mathrm{~A} \mathrm{~g}^{-1}$, (E) Raman spectrum of composite membrane showing both the $1 \mathrm{~T}$-MoS 2 peaks (enlarged in inset, $J_{1}, J_{2}, J_{3}, E_{2 \mathrm{~g}}$ and $A_{1 \mathrm{~g}}$ ) and graphene peaks $\left(D, G\right.$ and $2 D$ bands). (F) Capacitance retention of $1 \mathrm{~T}-\mathrm{MoS}_{2} / \mathrm{SEG}$ electrodes after $5,000 \mathrm{cycles}$ in $6.0 \mathrm{M} \mathrm{KOH}$ (aq 

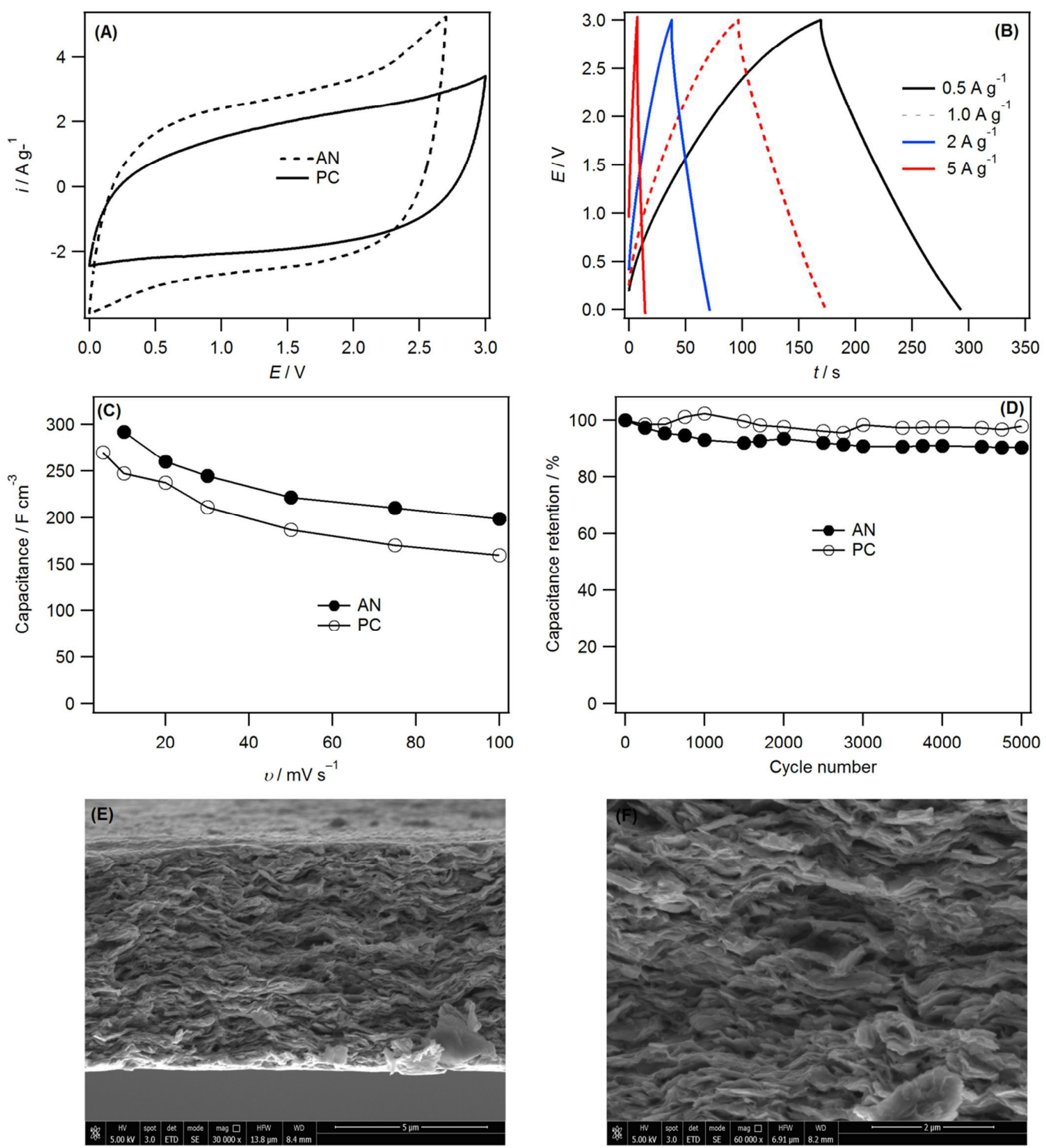

Figure 10 (A) Cyclic voltammograms recorded at $100 \mathrm{mV} \mathrm{s}^{-1}$ in $1.0 \mathrm{M}[\mathrm{TEA}]\left[\mathrm{BF}_{4}\right]$ in acetonitrile and $1.0 \mathrm{M}$ [TEA] $\left[\mathrm{BF}_{4}\right]$ in propylene carbonate using symmetrical coin cells constructed from $1 \mathrm{~T}-\mathrm{MoS}_{2} / \mathrm{SEG}$ electrodes. The voltage was scanned between $0.0 \mathrm{~V}$ (initial potential) and $2.7 \mathrm{~V}$ for acetonitrile and $0.0 \mathrm{~V}$ to $3.0 \mathrm{~V}$ for propylene carbonate, (B) galvanostatic charge-discharge curves obtained using $1.0 \mathrm{M}[\mathrm{TEA}]\left[\mathrm{BF}_{4}\right]$ in propylene carbonate at indicated currents, (C) Volumetric capacitance as a function of scan rates, (D) Capacitance retention of $1 \mathrm{~T}-\mathrm{MoS}_{2} / \mathrm{SEG}$ electrodes after 5,000 cycles and (E) and (F) shows the cross sectional SEM image of the free standing $1 \mathrm{~T}-\mathrm{MOS}_{2} / \mathrm{SEG}$ membrane 
AC impedance spectroscopy was also carried out to further determine the electrochemical behaviour of each electrode. Nyquist and Bode plots were obtained at open circuit potential over the frequency range $10 \mathrm{mHz}$ to $100 \mathrm{kHz}$ are shown in Figure 9C. The Nyquist plot of the composite electrode displayed a nearly vertical curve with low series resistance of $0.4 \Omega \mathrm{cm}^{2}$ while the cell made from $1 T-\mathrm{MoS}_{2}$ electrode showed a series resistance $1 \Omega \mathrm{cm}^{2}$ (Figure S5 for enlarged curve) and a transition from a linear looking feature to a classical Warburg impedance response occurred at a frequency of $2.6 \mathrm{~Hz}$. These observations, together with the fact that the Bode phase angle is close to $90^{\circ}$ at the composite electrode, meant that the cell is behaving close to an "ideal capacitor".

High volumetric capacitance is attractive for portable electronics and vehicles, ${ }^{53}$ as such, we also assessed the volumetric capacitance of the cell constructed using our composite electrode. Volumetric capacitances of $560 \mathrm{~F} \mathrm{~cm}^{-3}$ at $10 \mathrm{mV} \mathrm{s}^{-1}$ and $458 \mathrm{~F} \mathrm{~cm}^{-3}$ at $100 \mathrm{mV} \mathrm{s}^{-1}$ were obtained. These values are higher than the volumetric capacitance achieved using the best performing carbonbased electrodes. ${ }^{54,55}$ Lin et al. ${ }^{54}$ reported $490 \mathrm{~F} \mathrm{~cm}^{-3}$ in $\mathrm{Li}_{2} \mathrm{SO}_{4}(\mathrm{aq})$ with $\mathrm{N}$-doped mesoporous few-layer carbon at $2 \mathrm{mV} \mathrm{s}^{-1}$ and Yang et al. $^{55}$ reported $\sim 250 \mathrm{~F} \mathrm{~cm}^{-3}$ using restacked graphene sheets. Acerece et al. reported $\sim 450 \mathrm{~F} \mathrm{~cm}^{-3}$ in $\mathrm{KCl}(\mathrm{aq})$ and $700 \mathrm{~F} \mathrm{~cm}^{-3}$ in $\mathrm{H}_{2} \mathrm{SO}_{4}$ (aq) using chemically exfoliated $1 \mathrm{~T}-\mathrm{MoS}_{2}$, although it is likely that the values quoted are over-estimated due to parallel hydrogen evolution reactions that will occur under acidic conditions. ${ }^{7}$ Ghidiu et al. reported $900 \mathrm{~F} \mathrm{~cm}^{-3}$ in $\mathrm{H}_{2} \mathrm{SO}_{4}$ (aq) at $2 \mathrm{mV} \mathrm{s}^{-1}$ using conducting and hydrophilic $\mathrm{Ti}_{3} \mathrm{C}_{2}$ electrodes. ${ }^{56}$ While the gravimetric capacitance of our composite material is in the same range as for reduced graphene oxide-based electrodes, ${ }^{57}$ the volumetric capacitance of our composite material is twice that of most carbonbased electrodes. Galvanostatic charge-discharge cycling of the composite material between $0.0 \mathrm{~V}$ to $0.8 \mathrm{~V}$ at $1 \mathrm{~A} \mathrm{~g}^{-1}$ for 5,000 cycles exhibited excellent stability with a capacitance retention of over $92 \%$ (Figure 9F). Moreover, the serial resistance of the device did not increase by any notable amount after cycling. The small loss in capacitance indicates that there is no significant reversal of the material back to the $2 \mathrm{H}$-phase. This is consistent with the XPS analysis of the cycled $1 \mathrm{~T}-\mathrm{MoS}_{2}$ electrode reported by Chhowalla et $a l^{7}$, which showed the stability of the 1T-phase under potential cycling.

Finally, the composite electrode was tested using non-aqueous electrolytes to take advantage of their wide electrochemical window. Acetonitrile (AN) and propylene carbonate (PC) with tetraethylammonium tetrafluoroborate electrolyte were tested. As shown in Figure 10A, the AN-based electrolyte showed a potential window of $\sim 2.7 \mathrm{~V}$ whilst the PC-based electrolyte showed an enhanced potential window of $3.0 \mathrm{~V}$. Furthermore, examination of the $\mathrm{CV}$ and charge-discharge curve showed the composite electrode produced responses that are expected for capacitive behaviour. The volumetric capacitance of each electrolyte as a function of $v$ is shown in Figure 10C. Volumetric capacitances of $292 \mathrm{~F} \mathrm{~cm}^{-3}$ for AN and $247 \mathrm{~F} \mathrm{~cm}^{-3}$ for PC were obtained at $10 \mathrm{mV} \mathrm{s}^{-1}$ which are in close agreement with the ones obtained from charge-discharge at $0.5 \mathrm{~A} \mathrm{~g}$ ${ }^{1} ; 287 \mathrm{~F} \mathrm{~cm}^{-3}$ for $\mathrm{AN}$ and $206 \mathrm{~F} \mathrm{~cm}^{-3}$ for PC. Furthermore, the composite electrode showed excellent stability in PC electrolytes with more than $96 \%$ capacity retention after 5000 cycles while in AN the capacity retention was $\sim 90 \%$ (Figure 10D).
Energy and power densities as well as gravimetric and volumetric capacitance obtained at various discharge currents in each electrolyte are shown in Table S1. In general, the AN performed better than the PC electrolyte because of its lower viscosity, and associated lower solution resistance. In AN solutions, depending on the magnitude of discharge current, the energy densities varied between $0.08 \mathrm{Wh} \mathrm{cm}^{-3}$ and $0.28 \mathrm{Wh} \mathrm{cm}^{-3}$ with corresponding power densities between $1 \mathrm{~W} \mathrm{~cm}^{-3}$ and $18 \mathrm{~W} \mathrm{~cm}^{-3}$, while in the PC electrolyte the corresponding values were between $0.06-0.25 \mathrm{Wh} \mathrm{cm}^{-3}$ and $1.7-22 \mathrm{~W} \mathrm{~cm}^{-3}$. The Ragone plot generated using AN electrolyte in comparison to other best performing materials is shown in Figure 11 . The plot shows that the energy/power densities obtained at $1 \mathrm{~T}-\mathrm{MoS}_{2} /$ graphene composite are much higher than that obtained at carbon-based electrodes ${ }^{58-60}$ and slightly higher than those reported for chemically exfoliated 1T$\mathrm{MoS}_{2}$ electrodes (Figure 11). ${ }^{7}$ This demonstrates that the 1T-MoS $/$ graphene composite are attractive electrode for portable supercapacitor devices.

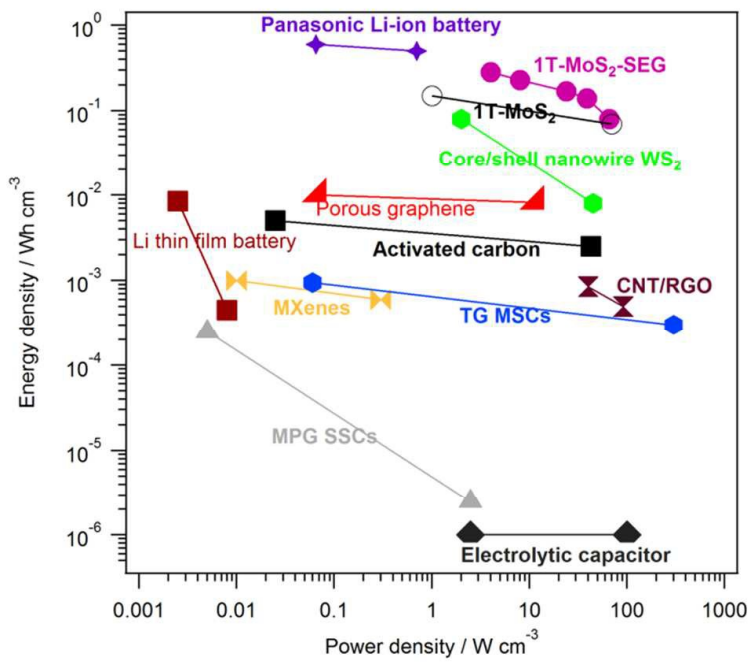

Figure 11. Ragone plot obtained using best performing volumetric energy and power densities reported from various materials consisting of $\mathrm{Li}$ thin film battery, ${ }^{61}$ Li-ion battery, ${ }^{61}$ MXenes, ${ }^{62}$ graphene, ${ }^{61,63}$ core/shell nanowire $\mathrm{WS}_{2}{ }^{64} 1 \mathrm{~T}-\mathrm{MoS}_{2}{ }^{7}$ and $1 \mathrm{~T}$ $\mathrm{MoS}_{2}$ /graphene composite.

In summary, a simple, scalable and rapid electrochemical method for preparation of metallic phase $\mathrm{MoS}_{2}$ nanosheets has been developed. Our methods differ from previous work in that the use of pyrophoric materials (such as organolithium compounds or metallic $\mathrm{Li}$ ) has been replaced with an inert $\mathrm{Li}$ salt and a $\mathrm{Pt}$ counter electrodes, which allowed the electrochemical intercalation process to be carried out with a benchtop setup. Characterisation of the exfoliated product using X-ray photoelectron spectroscopy, Raman spectroscopy and UV-visible absorption spectroscopy confirmed the formation of the 1T-phase with a concentration of $\sim 60 \%$. Importantly, this particular process can be used as a means for producing controlled trilayer $\mathrm{MoS}_{2}$ nanosheets. As demonstrated here, the exfoliated metallic phase $\mathrm{MoS}_{2}$ is a viable electrocatalyst for hydrogen evolution reaction and as an electrode material for supercapacitor. In particular, composite materials that were made from metallic phase $\mathrm{MoS}_{2}$ and graphene sheets showed 
an enhanced volumetric and gravimetric capacitance due to the synergistic coupling between individual components. The preparative route is cheap, simple, time efficient and should ultimately support the scalable production of metallic $\mathrm{MoS}_{2}$ as well as other transition metal dichlogenides such as $\mathrm{WS}_{2}, \mathrm{MoSe}_{2}$ and $\mathrm{WSe}_{2}$ for use in various applications. This method can also extended for production of semi-conducting phase $\mathrm{MoS}_{2}$ nanosheets if $1 \mathrm{~T}-\mathrm{MoS}_{2}$ is treated by heat

\section{Experimental Methods}

3.1 Materials and Reagents. $\operatorname{MoS}_{2}$ powder ( $99 \%, \sim 6 \mu \mathrm{m}$ ), lithium perchlorate $(99.99 \%)$, anhydrous dimethyl carbonate $(\geq 99 \%)$ and ethylene carbonate (99\%) were purchased from Sigma-Aldrich and used as received. $\mathrm{MoS}_{2}$ natural crystals were obtained from Manchester Nanomaterials Ltd. U.K. Polytetrafluroethylene was obtained from Omnipore membrane filters (JVWP01300) with a pore size of $0.2 \mu \mathrm{m}$ and Polyvinylidene fluoride was obtained from Durapore ${ }^{\circledR}$ membrane filters (vvlp01300, $0.1 \mu \mathrm{m}$ ). Millipore water $(18.2 \mathrm{M} \Omega \mathrm{cm})$ was obtained from a Milli-Q water purification system.

3.2 Electrochemical Intercalation of $\mathrm{Li}^{+}$into $\mathrm{MoS}_{2}$ : $\mathrm{A} \mathrm{MoS}_{2}$ pellet (Sigma, $99 \%$ with an average particle size of $6 \mu \mathrm{m}$ ) or a $\mathrm{MoS}_{2}$ natural crystal working electrode, a Pt mesh counter electrode and an $\mathrm{Ag}$ wire reference electrode were used for electrochemical measurements. The potential of an $\mathrm{Ag}$ wire was stable within a few $\mathrm{mV}$ over a $4 \mathrm{~h}$ period. The $\mathrm{MoS}_{2}$ pellet (12 $\mathrm{mm}$ diameter) was made by hydraulic pressing of the powder (0.4-1.0 g) at 2.5 tons. Prior to performing electrolysis, $\mathrm{N}_{2}$ gas was bubbled into the electrolyte for $30 \mathrm{~min}$ and during the electrochemical measurements an atmosphere of $\mathrm{N}_{2}$ was maintained above the electrolyte. The electrolyte consists of $1 \mathrm{M} \mathrm{LiClO}_{4}$ in a $1: 1 \mathrm{v} / \mathrm{v}$ mixture of dimethyl carbonate (DMC) and ethylene carbonate (EC). Electrochemical intercalation of $\mathrm{Li}^{+}$was performed using chronoamperometry by applying a potential of $-4.5 \mathrm{~V} v \mathrm{Ag}$ wire for $2 \mathrm{hr}$. The intercalated pellet was then rinsed with acetone and inserted immediately into deionised, deoxygenated water for exfoliation and followed by sonication for 30 mins. The resulting black suspension was added to a separating funnel and washed with $n$-hexane $(50 \mathrm{~mL})$ twice to extract any residual of organic impurities including the solid electrolyte interface. The concentrated black aqueous phase was collected and filtered using a PTFE membrane $(0.2 \mu \mathrm{m}$ pore size) and washed with $1 \mathrm{~L}$ of deionised water to remove excess lithium in the form of $\mathrm{LiOH}$. The resulting washed powder was re-dispersed in deionised water and sonicated for $20 \mathrm{~min}$, and then centrifuged at $1500 \mathrm{rpm}$ for $30 \mathrm{~min}$ to remove any non-exfoliated material as sediment yielding a highly stable dispersion.

3.3 Solution phase exfoliation of $\mathrm{MoS}_{2}$ to produce the $2 \mathrm{H}$ phase: For comparison, $2 \mathrm{H}$ phase $\mathrm{MoS}_{2}$ was produced using the ultrasonic exfoliation route developed by Coleman et. al.. ${ }^{65} 1.0 \mathrm{~g}$ of $\mathrm{MoS}_{2}$ powder (Sigma, $99 \%$ with average particle size of $6 \mu \mathrm{m}$ ) dissolved in $100 \mathrm{~mL}$ of water/isopropanol mixture $(1: 1 \mathrm{v} / \mathrm{v})$ was placed in a 250 $\mathrm{mL}$ round bottom flask. ${ }^{66}$ The mixture was then sonicated in a water bath sonicator (Elmasonic $\mathrm{P} 70 \mathrm{H}$ ) which operates at $37 \mathrm{kHz}$ and $40 \%$ amplitude for $12 \mathrm{~h}$ while cooling to maintain a stable temperature of $15^{\circ} \mathrm{C}$. The resulting suspension was centrifuged at $6000 \mathrm{rpm}$ twice for $30 \mathrm{~min}$ to remove any unexfoliated material. A stable dispersion of the supernatant was obtained and characterisation of the resulting suspension revealed that the exfoliated $\mathrm{MoS}_{2}$ was in the $2 \mathrm{H}$-phase.
3.4 Solution phase exfoliation of graphite: In a similar way to the $\mathrm{MoS}_{2}, 2.0 \mathrm{~g}$ of graphite powder (sigma) was dissolved in $100 \mathrm{~mL}$ of water/isopropanol mixture $(1: 1 \mathrm{v} / \mathrm{v})$ and sonicated for $18 \mathrm{~h}$ at 37 $\mathrm{kHz}$ and $40 \%$ amplitude as previously method. ${ }^{66}$ The resulting suspension was centrifuged at $6000 \mathrm{rpm}$ twice for $30 \mathrm{~min}$, and the supernatant collected for analysis.

3.5 Characterisation of the Exfoliated Product: Raman spectra were obtained using Renishaw inVia microscope with a $532 \mathrm{~nm}$ excitation laser operated at a low power of $0.274 \mathrm{~mW}$ with a 1800 $\mathrm{l} / \mathrm{mm}$ grating and a $100 \times$ objective. The sample for Raman measurement was prepared by drop coating the dispersion of $\mathrm{MoS}_{2}$ on to a $\mathrm{Si} / \mathrm{SiO}_{2}$ wafer which was then dried at room temperature. For AFM analysis the $\mathrm{MoS}_{2}$ dispersion was spray coated onto a $\mathrm{Si} / \mathrm{SiO}_{2}$ substrate which was dried in a vacuum oven at $40{ }^{\circ} \mathrm{C}$. SEM analysis was carried out using XL30 FEI Environmental scanning electron microscope or FEI Quanta 650 ESEM. Transmission electron microscopy and selected area electron diffraction (SAED) have been performed on FEI Talos at $200 \mathrm{kV}$. A FEI Titan 80-200 ChemiSTEM equipped with probe-side aberration correction and an X-FEG electron source was used for the aberration-corrected highresolution scanning transmission electron microscope (HRSTEM) imaging. STEM experiments were performed using an acceleration voltage of $200 \mathrm{kV}$, a convergence angle of $21 \mathrm{mrad}$ and a beam current of $90 \mathrm{pA}$. The inner and outer collection angles of the HAADF detector were 48 and $190 \mathrm{mrad}$, respectively. TEM and SAED data were also acquired on the FEI Titan microscope and the samples were prepared by drop casting the dispersion on holy carbon film (300 mesh $\mathrm{Cu}$, Agar Scientific) or on ultra-thin carbon support film (300 mesh Cu, Agar Scientific) TEM grid. Powder X-ray diffraction analysis was performed on free standing 1T-MoS membrane using Philips X'pert PRO diffractometer with $\mathrm{Cu} \mathrm{Ka}$ radiation $(\lambda=0.154 \mathrm{~nm})$ and operating at $40 \mathrm{kV}$ and $30 \mathrm{~mA}$. X-ray photoelectron spectroscopy (XPS) was performed using a Kratos Axis Ultra DLD spectrometer with a monochromated Al Ka X-ray source ( $E=1486.6 \mathrm{eV}, 10 \mathrm{~mA}$ emission), a hemispherical electron energy analyser and a multichannel plate and delay line detector (DLD). The samples for XPS were prepared by filtering $\mathrm{MoS}_{2}$ dispersion on PVDF membrane. UV-visible spectroscopy measurements were taken using a model DH-2000-BAL (Ocean Optics).

3.6 Electrode Preparation for Hydrogen Evolution Reaction: Hydrogen evolution reaction measurements were performed using a three-electrode cell consisting of a $3 \mathrm{~mm}$-diameter glassy carbon (GC) disk working electrode, an $\mathrm{Ag} \mid \mathrm{AgCl}$ reference electrode, and a Pt counter electrode (area of $1.2 \mathrm{~cm}^{2}$ ). Before use, GC working electrodes were polished with aqueous $0.3 \mu \mathrm{m}$ alumina (Buehler, Lake Bluff, IL) slurries on felt polishing pads and rinsed with deionized water. $\mathrm{GC}$ electrodes were modified with $10 \mu \mathrm{L}$ of the $\mathrm{MoS}_{2}$ dispersion (either $1 \mathrm{~T}-\mathrm{MoS}_{2}$ or $2 \mathrm{H}-\mathrm{MoS}_{2}$ ) and then dried at room temperature in air. Cyclic voltammograms (CVs) were recorded in $1 \mathrm{M} \mathrm{H}_{2} \mathrm{SO}_{4}$ at $5 \mathrm{mV} \mathrm{s}^{-1}$ which was deoxygenated prior to use by bubbling with $\mathrm{N}_{2}$ for 30 min. A blanket of $\mathrm{N}_{2}$ was maintained above the electrolyte during measurements. Electrochemical impedance spectroscopy (EIS) was performed in the frequency range from $100 \mathrm{kHz}$ to $100 \mathrm{mHz}$ at an oscillation amplitude of $5 \mathrm{mV}$ 
and an applied potential of $-0.45 \mathrm{~V} v$ s. $\mathrm{Ag} \mid \mathrm{AgCl}$. Impedance spectra were fitted to a Randles equivalent circuit model using Z-view software (Scribner Associates, Inc., Southern Pines, NC).

3.7 Electrode Preparation for Supercapacitor Testing: $\mathrm{MoS}_{2}$ electrodes were prepared by filtering a known volume of the dispersions onto a pre-weighed PVDF filter using a syringe pump dispenser (New Era Pump Systems, Inc, NY). The $\mathrm{MoS}_{2}$ membranes were then dried at room temperature in air. Coin cell assembly was prepared in standard CR2032 coin cell hardware with symmetrical active materials. The cells were assembled by stacking two symmetrical membranes back-to-back with the active material contacting the current collector. ${ }^{52}$ A few drops of the desired electrolyte (deoxygenated $6.0 \mathrm{M} \mathrm{KOH}$ (aq) or $1.0 \mathrm{M}$ tetraethylammonium tetrafluoroborate $\left([\mathrm{TEA}]\left[\mathrm{BF}_{4}\right]\right)$ in acetonitrile or propylene carbonate) was added to fill the electrode before the coin cell was sealed using a hydraulic crimping machine (MSK160D). Coin cell assembly was carried out in an Ar-filled globe box for the case of organic electrolytes. Gravimetric capacitance, volumetric capacitance, energy and power density were calculated using the best practice methods established in literature. ${ }^{7,67}$

3.8 1T-MoS ${ }_{2}$-graphene composite formulation: Prior to mixing 1T$\mathrm{MoS}_{2}$ with solution exfoliated graphene (SEG), a stock solution of $1 \mathrm{~T}-\mathrm{MoS}_{2}$ diluted with IPA to a concentration of $0.05 \mathrm{mg} \mathrm{mL}^{-1}$. After words, $50 \mathrm{~mL}$ of it mixed with $50 \mathrm{~mL}$ of SEG $\left(0.05 \mathrm{mg} \mathrm{mL}^{-1}\right)$ and sonicated for $20 \mathrm{~min}$

\section{ACKNOWLEDGMENT}

We would like to thank the European Union Seventh Framework Programme for funding, under grant agreement no. 604391 Graphene Flagship, and EPSRC (UK) for further financial support (Grant refs EP/K016954/1, EP/I023879/1). We also thank Samuel G. Booth for his assistance with TEM.

\section{References}

1. A. S. Arico, P. Bruce, B. Scrosati, J. M. Tarascon and W. van Schalkwijk, Nat. Mater., 2005, 4, 366-377.

2. Y. G. Guo, J. S. Hu and L. J. Wan, Adv. Mater., 2008, 20, 2878-2887.

3. F. Bonaccorso, L. Colombo, G. Yu, M. Stoller, V. Tozzini, A. C. Ferrari, R. S. Ruoff and V. Pellegrini, Science, 2015, 347, 1246501.

4. X. Y. Zhang, L. L. Hou, A. Ciesielski and P. Samori, Adv. Energy Mater., 2016, 6, 21.

5. M. A. Py and R. R. Haering, Can. J. Phys., 1983, 61, 76-84.

6. B. Radisavljevic, A. Radenovic, J. Brivio, V. Giacometti and A. Kis, Nat. Nanotechnol., 2011, 6, 147-150.

7. M. Acerce, D. Voiry and M. Chhowalla, Nat. Nanotechnol., 2015, 10, 313-318.

8. M. A. Lukowski, A. S. Daniel, F. Meng, A. Forticaux, L. S. Li and S. Jin, J. Am. Chem. Soc., 2013, 135, 10274-10277.

9. D. Voiry, M. Salehi, R. Silva, T. Fujita, M. W. Chen, T. Asefa, V. B. Shenoy, G. Eda and M. Chhowalla, Nano Lett., 2013, 13, 6222-6227.

10. C. Tan, W. Zhao, A. Chaturvedi, Z. Fei, Z. Zeng, J. Chen, Y. Huang, P. Ercius, Z. Luo, X. Qi, B. Chen, Z. Lai, B. Li, X. Zhang, J. Yang, Y. Zong, C. Jin, H. Zheng, C. Kloc and H. Zhang, Small, 2016, 12, 1866-1874.
11. X. M. Geng, W. W. Sun, W. Wu, B. Chen, A. Al-Hilo, M. Benamara, H. L. Zhu, F. Watanabe, J. B. Cui and T. P. Chen, Nat. Commun., 2016, 7.

12. Q. Tang and D.-e. Jiang, ACS Catal., 2016, 6, 4953-4961.

13. P. Joensen, R. F. Frindt and S. R. Morrison, Mater. Res. Bull., 1986, 21, 457-461.

14. B. K. Miremadi and S. R. Morrison, J. Catal., 1987, 103, 334-345.

15. G. Eda, H. Yamaguchi, D. Voiry, T. Fujita, M. W. Chen and M. Chhowalla, Nano Lett., 2011, 11, 5111-5116.

16. M. B. Dines, Mater. Res. Bull., 1975, 10, 287-291.

17. P. Joensen, E. D. Crozier, N. Alberding and R. F. Frindt, J. Phys. C: Solid State Phys., 1987, 20, 4043-4053.

18. J. Zheng, H. Zhang, S. H. Dong, Y. P. Liu, C. T. Nai, H. S. Shin, H. Y. Jeong, B. Liu and K. P. Loh, Nat. Commun., 2014, 5.

19. H. Zhang, Acs Nano, 2015, 9, 9451-9469.

20. V. H. Gessner, C. Daschlein and C. Strohmann, Chem. Eur. J., 2009, 15, 3320-3334.

21. Q. Liu, X. Li, Q. He, A. Khalil, D. Liu, T. Xiang, X. Wu and L. Song, Small, 2015, 11, 5556-5564.

$22 . \quad$ Z. Y. Zeng, T. Sun, J. X. Zhu, X. Huang, Z. Y. Yin, G. Lu, Z. X. Fan, Q. Y. Yan, H. H. Hng and H. Zhang, Angew. Chem. Int. Ed. Engl., 2012, 51, 9052-9056.

23. L. Oakes, R. Carter, T. Hanken, A. P. Cohn, K. Share, B. Schmidt and C. L. Pint, Nat. Commun., 2016, 7, 11796.

24. K. Chang and W. X. Chen, Acs Nano, 2011, 5, 4720-4728.

25. Y. Miki, D. Nakazato, H. Ikuta, T. Uchida and M. Wakihara, J. Power Sources, 1995, 54, 508-510.

26. T. Stephenson, Z. Li, B. Olsen and D. Mitlin, Energy Environ. Sci., 2014, 7, 209-231.

27. G. Du, Z. Guo, S. Wang, R. Zeng, Z. Chen and H. Liu, Chem. Commun., 2010, 46, 1106-1108.

28. K. Chang and W. Chen, ACS Nano, 2011, 5, 4720-4728.

29. J. Xiao, D. Choi, L. Cosimbescu, P. Koech, J. Liu and J. P. Lemmon, Chem. Mater., 2010, 22, 4522-4524.

30. Z. Y. Zeng, Z. Y. Yin, X. Huang, H. Li, Q. Y. He, G. Lu, F. Boey and H. Zhang, Angew. Chem. Int. Ed. Engl., 2011, 50, 11093-11097.

31. D. Voiry, A. Mohite and M. Chhowalla, Chem. Soc. Rev., 2015, 44, 2702-2712.

32. C. Lee, H. Yan, L. E. Brus, T. F. Heinz, J. Hone and S. Ryu, Acs Nano, 2010, 4, 2695-2700.

33. S. J. Sandoval, D. Yang, R. F. Frindt and J. C. Irwin, Phys. Rev. B, 1991, 44, 3955-3962.

34. M. Calandra, Phys. Rev. B, 2013, 88, 6 .

35. M. Velicky, M. A. Bissett, C. R. Woods, P. S. Toth, T. Georgiou, I. A. Kinloch, K. S. Novoselov and R. A. W. Dryfe, Nano Lett., 2016, 16, 2023-2032.

36. X. B. Fan, P. T. Xu, Y. C. Li, D. K. Zhou, Y. F. Sun, M. A. T. Nguyen, M. Terrones and T. E. Mallouk, J. Am. Chem. Soc., 2016, 138, 5143-5149.

37. G. Eda, T. Fujita, H. Yamaguchi, D. Voiry, M. W. Chen and M. Chhowalla, Acs Nano, 2012, 6, 7311-7317.

38. J. P. Wilcoxon, P. P. Newcomer and G. A. Samara, J. Appl. Phys. (Melville, NY, U. S.), 1997, 81, 7934-7944.

39. Y. T. Liu, X. D. Zhu, Z. Q. Duan and X. M. Xie, Chem. Commun., 2013, 49, 10305-10307.

40. C. A. Papageorgopoulos and W. Jaegermann, Surf. Sci., 1995, 338, 83-93. 
41.

R. Kappera, D. Voiry, S. E. Yalcin, B. Branch, G. Gupta, A. D. Mohite and M. Chhowalla, Nat. Mater., 2014, 13, 11281134.

42. C. M. Julien, Mater. Sci. Eng., R, 2003, 40, 47-102.

43. M. Wang, L. Chen and L. C. Sun, Energy Environ. Sci., 2012, 5, 6763-6778.

44. Y. Li, H. Wang, L. Xie, Y. Liang, G. Hong and H. Dai, J. Am. Chem. Soc., 2011, 133, 7296-7299.

45. B. Hinnemann, P. G. Moses, J. Bonde, K. P. Jørgensen, J. H. Nielsen, S. Horch, I. Chorkendorff and J. K. Nørskov, J. Am. Chem. Soc., 2005, 127, 5308-5309.

46. T. F. Jaramillo, K. P. Jorgensen, J. Bonde, J. H. Nielsen, S. Horch and I. Chorkendorff, Science, 2007, 317, 100-102.

47. J. Kibsgaard, Z. B. Chen, B. N. Reinecke and T. F. Jaramillo, Nat. Mater., 2012, 11, 963-969.

48. C. Tsai, F. Abild-Pedersen and J. K. Norskov, Nano Lett., 2014, 14, 1381-1387.

49. Y. G. Li, H. L. Wang, L. M. Xie, Y. Y. Liang, G. S. Hong and H. J. Dai, J. Am. Chem. Soc., 2011, 133, 7296-7299.

50. E. Navarro-Flores, Z. W. Chong and S. Omanovic, J. Mol. Catal. A: Chem., 2005, 226, 179-197.

51. B. Børresen, G. Hagen and R. Tunold, Electrochim. Acta, 2002, 47, 1819-1827.

52. M. A. Bissett, I. A. Kinloch and R. A. W. Dryfe, ACS Appl. Mater. Interfaces, 2015, 7, 17388-17398.

53. Y. Gogotsi and P. Simon, Science, 2011, 334, 917-918.

54. T. Q. Lin, I. W. Chen, F. X. Liu, C. Y. Yang, H. Bi, F. F. Xu and F. Q. Huang, Science, 2015, 350, 1508-1513.

55. X. W. Yang, C. Cheng, Y. F. Wang, L. Qiu and D. Li, Science, 2013, 341, 534-537.

56. M. Ghidiu, M. R. Lukatskaya, M.-Q. Zhao, Y. Gogotsi and M. W. Barsoum, Nature, 2014, 516, 78-81.

57. M. D. Stoller, S. J. Park, Y. W. Zhu, J. H. An and R. S. Ruoff, Nano Lett., 2008, 8, 3498-3502.

58. E. Raymundo-Pinero, M. Cadek and F. Beguin, Adv. Funct. Mater., 2009, 19, 1032-1039.

59. S. Murali, N. Quarles, L. L. Zhang, J. R. Potts, Z. Q. Tan, Y. L. Lu, Y. W. Zhu and R. S. Ruoff, Nano Energy, 2013, 2, 764768.

60. Z. Chen, J. Wen, C. Z. Yan, L. Rice, H. Sohn, M. Q. Shen, M. Cai, B. Dunn and Y. F. Lu, Adv. Energy Mater., 2011, 1, 551-556.

61. Z. S. Wu, K. Parvez, X. L. Feng and K. Mullen, Nat. Commun., 2013, 4, 2487.

62. M. R. Lukatskaya, O. Mashtalir, C. E. Ren, Y. Dall'Agnese, P. Rozier, P. L. Taberna, M. Naguib, P. Simon, M. W. Barsoum and Y. Gogotsi, Science, 2013, 341, 1502-1505.

63. Y. Tao, X. Y. Xie, W. Lv, D. M. Tang, D. B. Kong, Z. H. Huang, H. Nishihara, T. Ishii, B. H. Li, D. Golberg, F. Y. Kang, T. Kyotani and Q. H. Yang, Sci. Rep., 2013, 3.

64. N. Choudhary, C. Li, H. S. Chung, J. Moore, J. Thomas and Y. Jung, Acs Nano, 2016, 10, 10726-10735.

65. J. N. Coleman, M. Lotya, A. O'Neill, S. D. Bergin, P. J. King, U. Khan, K. Young, A. Gaucher, S. De, R. J. Smith, I. V. Shvets, S. K. Arora, G. Stanton, H.-Y. Kim, K. Lee, G. T. Kim, G. S. Duesberg, T. Hallam, J. J. Boland, J. J. Wang, J. F. Donegan, J. C. Grunlan, G. Moriarty, A. Shmeliov, R. J. Nicholls, J. M. Perkins, E. M. Grieveson, K. Theuwissen, D. W. McComb, P. D. Nellist and V. Nicolosi, Science, 2011, 331, 568-571.

66. U. Halim, C. R. Zheng, Y. Chen, Z. Y. Lin, S. Jiang, R. Cheng, Y. Huang and X. F. Duan, Nat. Commun., 2013, 4, 7.
67. M. D. Stoller and R. S. Ruoff, Energ \& Environ Sc., 2010, 3, 1294-1301. 


\section{Graphical abstract}

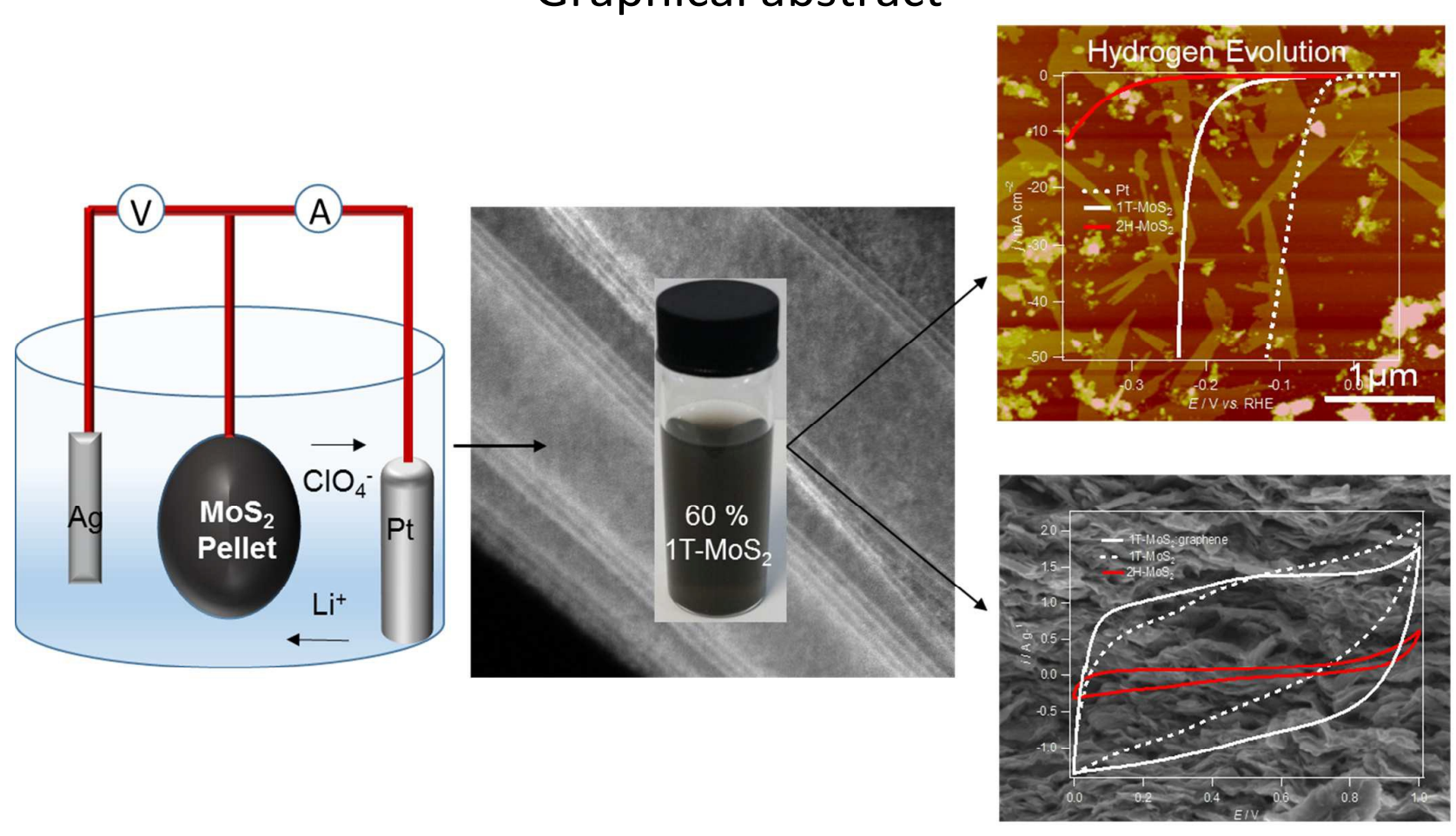

